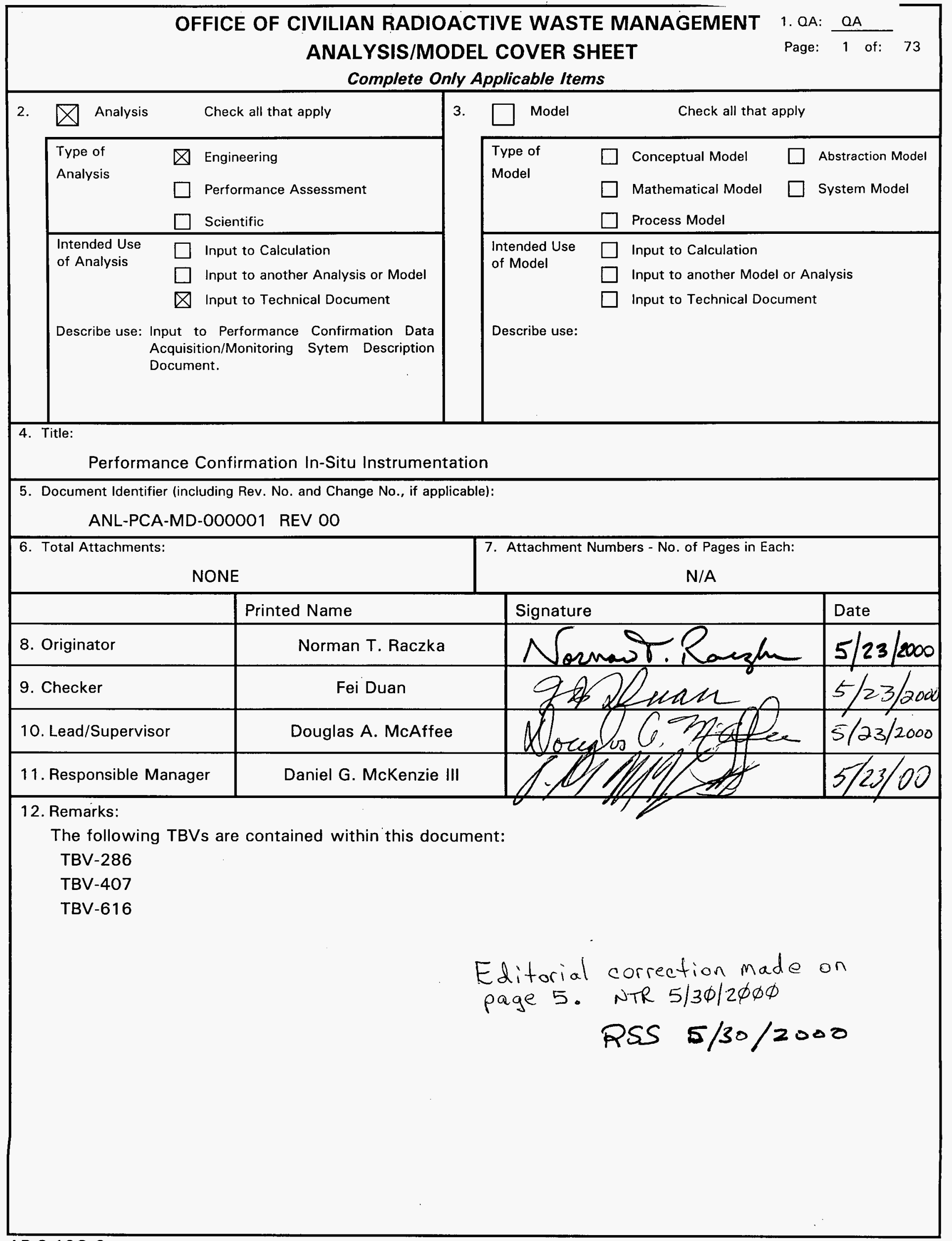


Complete On/y Applicable Items

2. Analysis or Model Title:

Performance Confirmation In-Situ Instrumentation

3. Document Identifier (including Rev. No. and Change No., if applicable):

ANL-PCA-MD-000001 REV 00

4. Revision/Change No.

5. Description of Revision/Change

\begin{tabular}{|l|l}
\hline OO & Initial Issue
\end{tabular}




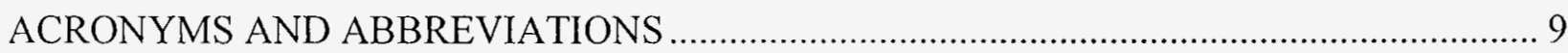

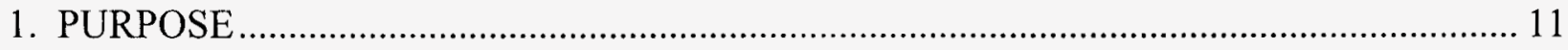



3. COMPUTER SOFTWARE AND MODEL USAGE ……………………………............ 15

4. INPUTS

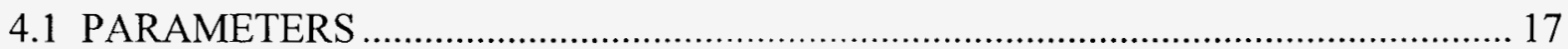

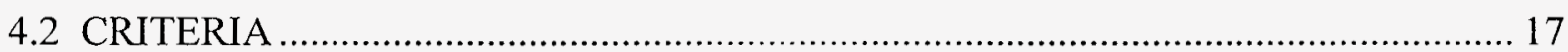

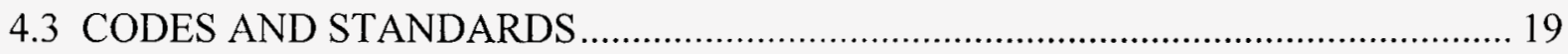

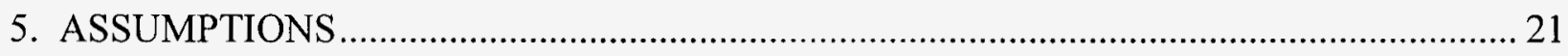

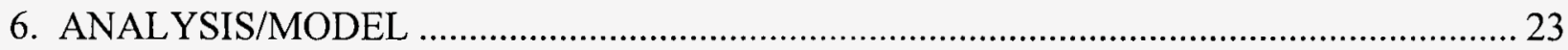

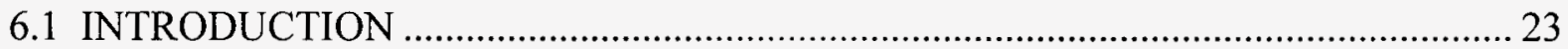

6.2 IN-SITU PARAMETERS TO BE MONITORED ……............................................ 23

6.3 PERFORMANCE CONFIRMATION DATA ACQUISITION STRATEGY................. 25

6.4 IN-SITU METHODS FOR REPOSITORY DATA ACQUISITION ….........................2 27

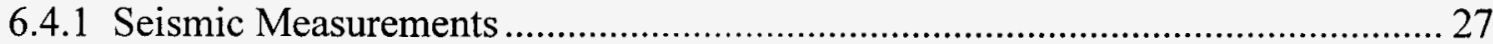

6.4.2 Rock Mass Hydrologic Properties ………………........................................... 28



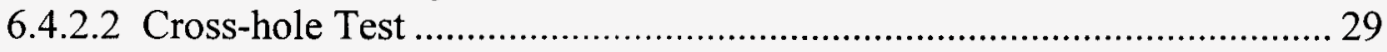

6.4.2.3 Constant Drawdown Test.................................................................... 30

6.4.2.4 Constant Discharge Test ................................................................... 30

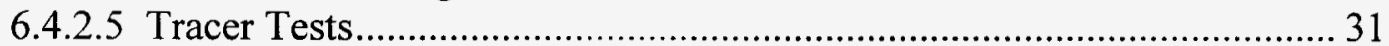



6.4.3 Rock Mass Pneumatic Properties ...................................................................... 32

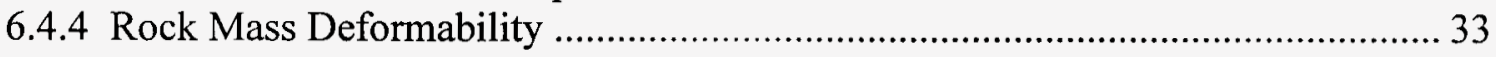

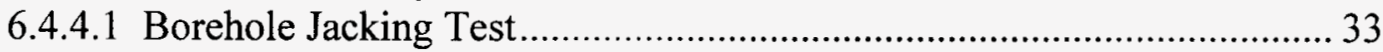

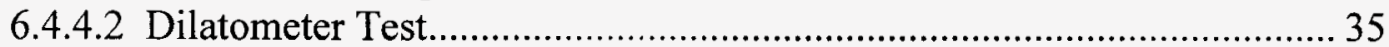

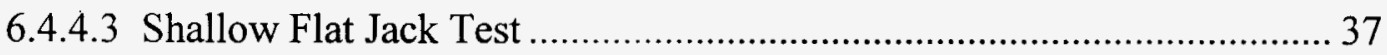



6.4.4.5 Recommendations for Determining Rock Mass Deformability .............. 39

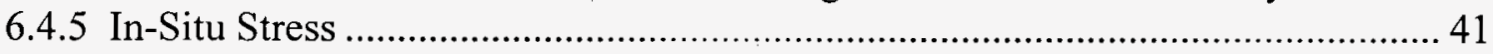

6.4.5.1 Shallow Flat Jack Test .............................................................. 42

6.4.5.2 USBM Gauge With Overcoring ............................................................... 42

6.4.5.3 Doorstopper Biaxial Strain Cell With Overcoring.................................... 45

6.4.5.4 CSIRO Triaxial Strain Cell With Overcoring............................................ 46

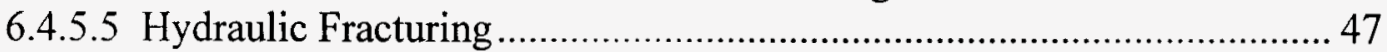

6.4.5.6 Recommended Procedures for Determination of In-Situ Stress ............. 49



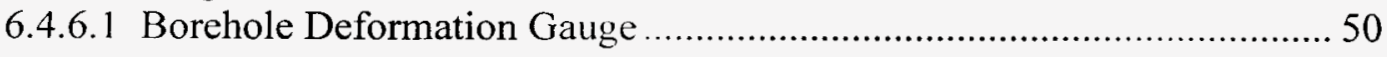




\section{CONTENTS (Continued)}



6.4.6.3 Borehole Pressure Cells (BPCs) …………........................................ 51

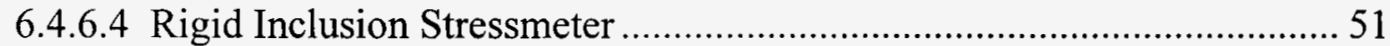

6.4.6.5 Borehole Inclusion Strain Cells ........................................................... 52

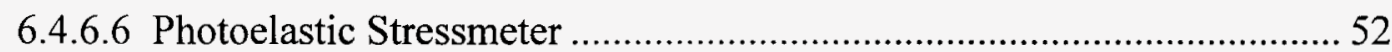

6.4.6.7 Recommended Procedures for Determining Stress Change ………….... 53

6.4.7 Rock Mass Strength....................................................................................... 53

6.4.7.1 In-Situ Triaxial Compression Test ........................................................ 53

6.4.7.2 In-Situ Direct Shear Test ................................................................ 54

6.4.7.3 In-Situ Torsional Shear Test .................................................................. 54

6.4.7.4 Recommended Procedures for Determining Rock Strength.................... 54

6.4.8 Temperature Measurements ......................................................................... 54

6.4.8.1 Thermocouple .................................................................................. 55

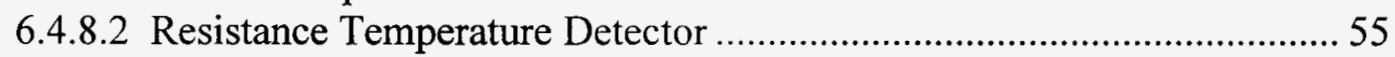

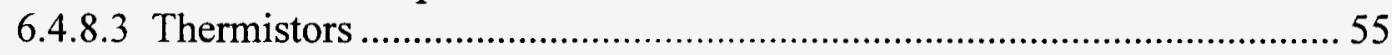





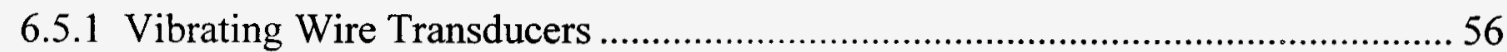

6.5.2 Multi-Point Borehole Extensometers ………………............................................ 57

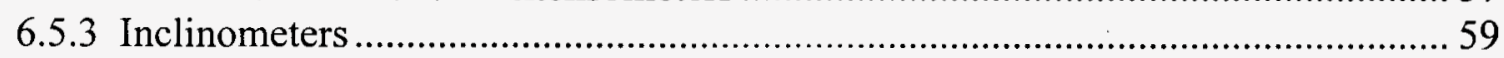

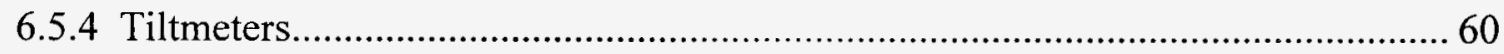

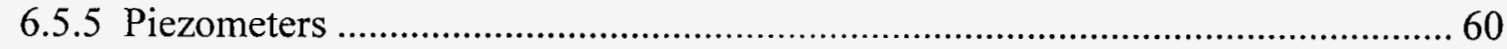





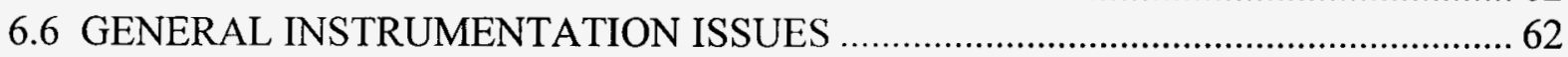

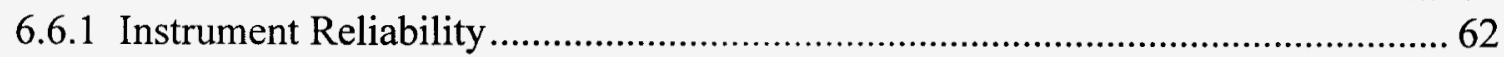

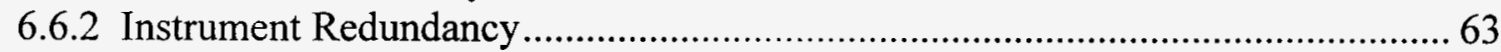

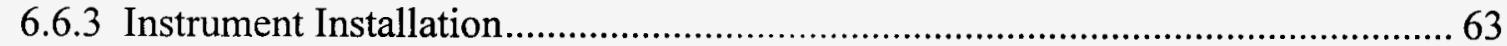

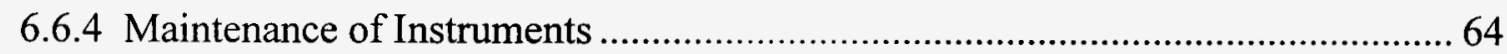



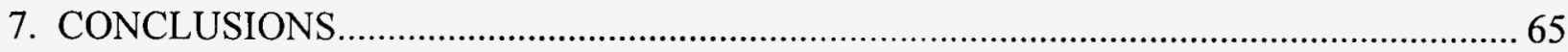

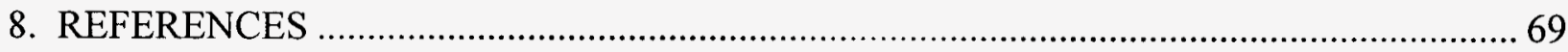

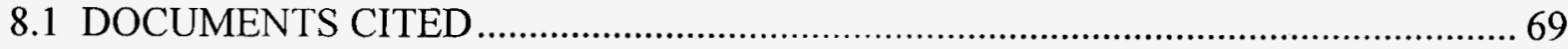

8.2 CODES, STANDARDS, REGULATIONS AND PROCEDURES ............................... 70

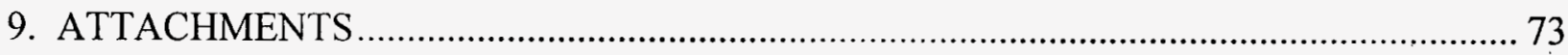




\section{FIGURES}

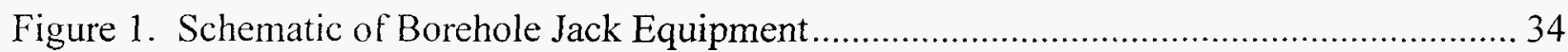

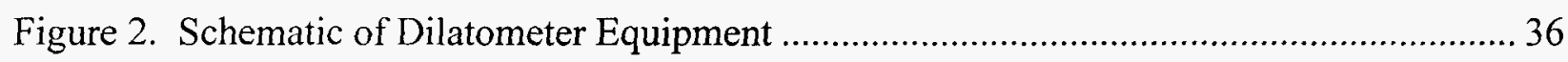

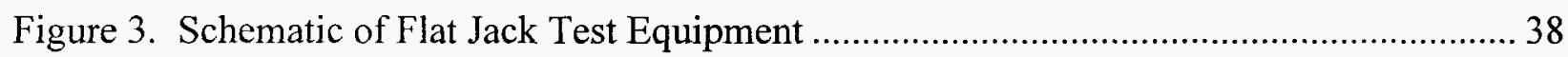

Figure 4. Schematic of Rigid Plate Jacking Test Equipment.................................................... 40

Figure 5. Test Sequence for Determination of In-Situ Stress Utilizing the USBM Borehole Deformation

Gauge

N5/3 $\phi 12 \phi \phi \phi$ 
INTENTIONALLY LEFT BLANK 


\section{TABLES}

Table 1. Seismic Parameters.

Table 2. Rock Mass Hydraulic Parameters

Table 3. Rock Mass Pneumatic Parameters

Table 4. Rock Mass Mechanical Parameters 18

Table 5. Rock Mass Thermal Parameters 18

Table 6. Hydraulic Groundwater Monitoring Parameters 18

Table 7. Thermal Groundwater Monitoring Parameters 18

Table 8. Advantages and Limitations of Rod-type Borehole Extensometers with Remote Electrical Readout 
INTENTIONALLY LEFT BLANK 


\section{ACRONYMS AND ABBREVIATIONS}

\section{$\underline{\text { ACRONYMS }}$}

$\begin{array}{ll}\text { ASTM } & \begin{array}{l}\text { American Society for Testing and Materials } \\ \text { AZ }\end{array} \\ \text { BPC } & \text { borehole pressure cell } \\ \text { CPC } & \begin{array}{l}\text { cylindrical pressure cell } \\ \text { CSIR }\end{array} \\ \text { CSIRO } & \begin{array}{l}\text { Council for Scientific and Industrial Research } \\ \text { LVDT }\end{array} \\ \text { PC } & \text { Linear Variable Displacement Transducer } \\ \text { PCDAMS } & \begin{array}{l}\text { Performance Confirmation } \\ \text { PTD }\end{array} \\ \text { RTD } & \text { resistance temperature detector } \\ \text { USBM } & \text { United States Bureau of Mines }\end{array}$

\section{ABBREVIATIONS}

$\begin{array}{ll}\mathrm{mm} & \begin{array}{l}\text { millimeters } \\ \text { meganewtons } \\ \text { megapascals }\end{array} \\ \mathrm{MPa} & \text { degrees Celsius }\end{array}$


INTENTIONALLY LEFT BLANK 


\section{PURPOSE}

The purpose of this document is to identify and analyze the types of in-situ instruments and methods that could be used in support of the data acquisition portion of the Performance Confirmation (PC) program at the potential nuclear waste repository at Yucca Mountain. The PC program will require geomechanical, geophysical, thermal, and hydrologic instrumentation of several kinds. This analysis is being prepared to document the technical issues associated with each type of measurement during the PC period.

This analysis utilizes the Performance Confirmation Input Criteria (CRWMS M\&O 1999a) as its starting point. The scope of this analysis is primarily on the period after the start of waste package emplacement and before permanent closure of the repository, a period lasting between 15 and 300 years after last package emplacement (Stroupe 2000, Attachment 1, p. 1).

The primary objectives of this analysis are to:

- Review the design criteria as presented in the Performance Confirmation Input Criteria (CRWMS M\&O 1999a). The scope of this analysis will be limited to the instrumentation related to parameters that require continuous monitoring of the conditions underground.

- Preliminary identification and listing of the data requirements and parameters as related to the current repository layout in support of PC monitoring.

- Preliminary identification of methods and instrumentation for the acquisition of the required data.

Although the Performance Confirmation Input Criteria (CRWMS M\&O 1999a) defines a broad range of data that must be obtained from a variety of methods, the focus of this analysis is on instrumentation related to the performance of the rock mass and the formation of water in the repository environment, that is obtainable from in-situ observation, testing, and monitoring. This analysis does not address the following types of data acquisition:

- Exploratory borings from the surface and borehole logging

- Geophysical exploration conducted from the surface

- Laboratory testing

- Mapping data

- General industrial instrumentation, such as that required to control ventilation systems

- Radioactivity monitoring

- Data acquired using manual techniques 
Certain data may be obtained only by analytical derivation from acquired data. Such analytical derivations will be identified where appropriate, but development of the necessary tools, computer programs, or systems for the analytical derivations will not be discussed in this analysis.

Performance Confirmation activities will be identified by a PC working group comprised of various organizations of the CRWMS M\&O. This working group, perhaps better described as the PC team, will be a special test and analysis group charged with the responsibility to define and conduct PC activities for the MGR. This team, however, is expected to evolve into a more structured test organization before the start of repository construction, as described in the Monitored Geologic Repository Test and Evaluation Plan (CRWMS M\&O 1998, pp. 3-14 to 316). The recommendations presented in this analysis are initial efforts regarding the use and types of possible in-situ instrumentation for obtaining the required data. It is anticipated that members of the $\mathrm{PC}$ team will determine the final instrument selection.

This analysis is being prepared in accordance with the Development Plan (CRWMS M\&O 1999d) approved on August 11, 1999. 


\section{QUALITY ASSURANCE}

Many different types of instruments will be used to acquire data in support of the PC Program. These instruments have been classified in accordance with QAP-2-3, Classification of the MGR Performance Confirmation Data Acquisition/Monitoring System, and have been found to be quality affecting (CRWMS M\&O 1999b, p. 7). They are also on the project Q-list (YMP 1998, Attachment II, p. 23-24).

The preparation of this design analysis has been conducted in accordance with AP-3-10Q, Analyses and Models, and has been evaluated in accordance with QAP-2-0, Performance Confirmation - 99 Work Package 12012383M1, (CRWMS M\&O 1999c). The activity evaluation has determined this analysis to be quality affecting subject to the requirements of the Quality Assurance Requirements and Description (DOE 2000). 
INTENTIONALLY LEFT BLANK 


\section{COMPUTER SOFTWARE AND MODEL USAGE}

Not Applicable. The Project-standard suite of office software for word processing has been used in the preparation of this analysis. The figures have been drawn using Project-standard Computer Aided Design Drafting programs. These are commercially available software programs, that are appropriate for the application, approved for the Project, and no special qualifications are needed. 
INTENTIONALLY LEFT BLANK 


\section{INPUTS}

\subsection{PARAMETERS}

This section is not applicable. There are no scientific parameter values that are needed for this analysis.

\subsection{CRITERIA}

4.2.1 The PCDAMS shall provide features for periodic monitoring of the seismic parameters listed in Table 1 (CRWMS M\&O 1999a, p. 9).

Table 1. Seismic Parameters

\begin{tabular}{|l|}
\hline \multicolumn{1}{|c|}{ Parameter } \\
\hline Hypocentral Location (TBV-616) \\
\hline Magnitude (TBV-616) \\
\hline Acceleration/ground motion (TBV-616) \\
\hline
\end{tabular}

4.2.2 The PCDAMS shall provide features for hydraulic testing and sampling in the unsaturated zone of the rock mass in the altered zone (AZ) and in rock fracture zones, as identified in Table 2 (CRWMS M\&O 1999a, p. 11).

Table 2. Rock Mass Hydraulic Parameters

\begin{tabular}{|l|}
\hline \multicolumn{1}{|c|}{ Parameter } \\
\hline Saturated Hydraulic Conductivity/Permeability (TBV-616) \\
\hline Effective Porosity (TBV-616) \\
\hline Dispersivity/Dispersion Coefficient (TBV-616) \\
\hline Hydraulic Potential - Moisture Content Relationship (TBV-616) \\
\hline Moisture Content - Hydraulic Conductivity Relationship (TBV-616) \\
\hline
\end{tabular}

4.2.3 The PCDAMS shall provide features for pneumatic testing and sampling in the unsaturated zone of the rock mass in the $\mathrm{AZ}$ and in underground rock fracture zones (including faults) as identified in Table 3 (CRWMS M\&O 1999a, p. 11).

Table 3. Rock Mass Pneumatic Parameters

\begin{tabular}{|l|}
\hline \multicolumn{1}{|c|}{ Parameter } \\
\hline Air Permeability (TBV-616) \\
\hline Gaseous Dispersion Coefficient (TBV-616) \\
\hline
\end{tabular}

4.2.4 The PCDAMS shall provide features for periodic mechanical monitoring in the unsaturated zone of the rock mass in the AZ, as identified in Table 4 (CRWMS M\&O 1999a, p. 11) 
Table 4. Rock Mass Mechanical Parameters

\begin{tabular}{|l|}
\hline \multicolumn{1}{c|}{ Parameter } \\
\hline Strain (TBV-616) \\
\hline Rock Deformation and Displacement (TBV-616) \\
\hline
\end{tabular}

4.2.5 The PCDAMS shall provide features for periodic thermal monitoring in the unsaturated zone of rock mass in the AZ, far-field, and rock fracture zones (including faults), as identified in Table 5 (CRWMS M\&O 1999a, p. 12).

Table 5. Rock Mass Thermal Parameters

\begin{tabular}{|l|}
\hline \multicolumn{1}{|c|}{ Parameter } \\
\hline Far-field and Rock Temperature (TBV-616) \\
\hline Altered Zone and Rock Temperature (TBV-616) \\
\hline
\end{tabular}

4.2.6 The PCDAMS shall provide features for periodic hydraulic monitoring of groundwater in the underground rock matrix, rock fracture zones (including faults), and other discontinuities in the unsaturated zone, as identified in Table 6 (CRWMS M\&O 1999a, p. 13)

Table 6. Hydraulic Groundwater Monitoring Parameters

\begin{tabular}{|l|}
\hline \multicolumn{1}{|c|}{ Parameter } \\
\hline In-Situ Fluid Potential (TBV-616) \\
\hline Far-Field Moisture Content (TBV-616) \\
\hline Altered Zone Moisture Content (TBV-616) \\
\hline Far-Field Water Vapor Content/Humidity (TBV-616) \\
\hline Altered Zone Water Vapor Content/Humidity (TBV-616) \\
\hline
\end{tabular}

4.2.7 The PCDAMS shall provide features for periodic thermal monitoring of groundwater in underground rock matrix, rock fracture zones (including faults), and other discontinuities in the unsaturated zone, as identified in Table 7 (CRWMS M\&O 1999a, p. 13)

Table 7. Thermal Groundwater Monitoring Parameters

\begin{tabular}{|l|}
\hline \multicolumn{1}{|c|}{ Parameter } \\
\hline Far-Field Fluid Temperature (TBV-616) \\
\hline Altered Zone Fluid Temperature (TBV-616) \\
\hline
\end{tabular}

4.2.8 The PCDAMS shall provide features for periodic air pressure monitoring of subsurface air and gases (TBV-616) in the underground rock matrix, rock fracture zones (including faults), and other discontinuities in the unsaturated zone (CRWMS M\&O 1999a, p. 13).

4.2.9 The PCDAMS shall provide features for monitoring the temperature of the zeolite layer $170 \mathrm{~m}$ (TBV-286) below the emplacement area horizon (CRWMS M\&O 1999a, p. 16). 
4.2.10 The PCDAMS shall provide features for monitoring the temperature of the PTn geologic unit (CRWMS M\&O 1999a, p. 16).

\subsection{CODES AND STANDARDS}

\subsubsection{American Society for Testing and Materials (ASTM)}

ASTM D 4394-84 Standard Test Method for Determining the In-Situ Modulus of Deformation of Rock Mass Using the Rigid Plate Loading Method

ASTM D 4403-84 Standard Practice for Extensometers Used in Rock

ASTM D 4622-86 Standard Test Method for Rock Mass Monitoring Using Inclinometers

ASTM D 4623-96 Standard Test Method for Determination of In-Situ Stress in Rock Mass by Overcoring Method - USBM Borehole Deformation Gage

ASTM D 4645-87 Standard Test Method for Determination of the In-Situ Stress in Rock Using the Hydraulic Fracturing Method

ASTM D 4729-87 Standard Test Method for In-Situ Stress and Modulus of Deformation Using the Flatjack Method

ASTM D 4971-89 Standard Test Method for Determining the In-Situ Modulus of Deformation of Rock Using the Diametrically Loaded 76-mm (3-in.) Borehole Jack

ASTM D 6230-98 Standard Test Method for Monitoring Ground Movement Using Probe-Type Inclinometers 
INTENTIONALLY LEFT BLANK 


\section{ASSUMPTIONS}

No assumptions were used in the preparation of this analysis. This is a preliminary analysis to discuss the types of instrumentation that may be used in the PC Program. 
INTENTIONALLY LEFT BLANK 


\section{ANALYSIS/MODEL}

\subsection{INTRODUCTION}

Performance Confirmation is defined in the Revised Interim Guidance Pending Issuance of New U.S. Nuclear Regulatory Commission (NRC) Regulations (Revision 01, July 22, 1999), for Yucca Mountain, Nevada (Dyer 1999, section 2) as "the program of tests, experiments, and analysis that is conducted to evaluate the accuracy and adequacy of the information used to determine with reasonable assurance that the performance objective at Sec. 113(b) will be met." Section 113(b) states "The engineered barrier system shall be designed so that, working in combination with natural barriers, the expected annual dose to the average member of the critical group shall not exceed $0.25 \mathrm{mSv}(25 \mathrm{mrem})$ total effective dose equivalent (TEDE) at any time during the first 10,000 years after permanent closure, as a result of radioactive materials released from the geologic repository." Subpart F of the Revised Interim Guidance Pending Issuance of New U.S. Nuclear Regulatory Commission (NRC) Regulations (Revision 01, July 22, 1999), for Yucca Mountain, Nevada (Dyer 1999, section 131 - 143) provides general requirements for a PC program, as well as more specific requirements related to the confirmation of geotechnical and design parameters, design testing, and monitoring and testing of waste packages.

The PC Program objectives are (CRWMS M\&O 2000, p. 2-1):

- To provide data that indicate subsurface conditions and any changes during construction and waste emplacement fall within the limits assumed in the license application.

- To provide data that indicate natural and engineered barrier systems and components required for repository operations (or designed or assumed to operate as barriers after permanent closure) are functioning as intended and anticipated.

- To evaluate compliance with NRC requirements related to post-closure performance.

- To comply with the requirements necessary for the authorization of permanent closure.

The Monitored Geologic Repository PC program will test and evaluate the natural and engineered barrier systems of the repository to predict post-closure waste confinement and isolation performance. It will rely on in-situ monitoring, field and laboratory tests, and experiments to collect data during repository construction and operation. The data will be used to confirm predictions, evaluate pre-closure performance, and recommend corrective actions or repository closure. This analysis will focus on discussions regarding the in-situ methods and field instrumentation necessary to transmit the data to the data acquisition system for further analysis, evaluation, and storage.

\subsection{IN-SITU PARAMETERS TO BE MONITORED}

If data acquired from the $\mathrm{AZ}$ using in-situ instrumentation is desired, access to the instruments must be maintained to allow for repair and calibration. (Note: The term "altered zone" refers to the geologic region affected thermomechanically by waste package emplacement, and is 
discussed further in the Near-Field/Altered-Zone Models Report, (Hardin 1998, p. 1-1 and 1-2)). The placement of instrumentation within the emplacement drifts requires additional design effort and investigation. Another concept that can be utilized for acquisition of this $\mathrm{AZ}$ data involves the drilling of boreholes from non-emplacement areas into the $\mathrm{AZ}$ surrounding the emplacement drifts. Observation drifts can be excavated to serve as the primary locations from which the boreholes could be drilled and instrumentation installed and maintained. The number, layout, and configuration of the observation drifts are the subject of a separate analysis (see CRWMS M\&O 1997, p. 77).

The source for the development of the following list of parameters is the Performance Confirmation Input Criteria (CRWMS M\&O 1999a) prepared in August, 1999. This document is basically a Systems Description Document. A Systems Description Document presents the specific design criteria, describes the design, and shows how these criteria are satisfied by the design. In its current stage of development, this Systems Description Document consists of system functions and design criteria only. Documents such as this analysis will assist in describing the design and will supplement the System Description Document.

- Seismic Parameters

- Hypocentral Location

- Magnitude

- Acceleration/ground motion

- Rock Mass Hydraulic Parameters

- Saturated hydraulic conductivity/permeability

- Effective porosity

- Dispersivity/dispersion coefficient

- Hydraulic potential-moisture content relationship

- Moisture content-hydraulic conductivity relationship

- Rock Mass Pneumatic Parameters

- Air permeability

- Gaseous dispersion coefficient

- Rock Mass Mechanical Parameters

- Strain

- Rock deformation

- Rock Mass Thermal Parameters

- Far-field rock temperature

- AZ rock temperature 
- Hydraulic Groundwater Monitoring Parameters

- In-situ fluid potential

- Far-field moisture content

- AZ moisture content

- Far-field water vapor content/humidity

- AZ water vapor content/humidity

- Thermal Groundwater Monitoring Parameters

- Far-field fluid temperature

- AZ fluid temperature

Sources, such as the Performance Confirmation Input Criteria (CRWMS M\&O 1999a), have been used for guidance, with the objective of producing a list of measurable parameters, but not to list all derivative parameters or properties that can be obtained from the measurable parameters. For example, the measurement of thermal conductivity may be important to know for PC purposes, however, this property is determined from temperature measurements (by resistance temperature detector (RTD), thermocouple) at various locations. In this case, therefore, temperature is the basic parameter to be measured, not thermal conductivity.

\subsection{PERFORMANCE CONFIRMATION DATA ACQUISITION STRATEGY}

To predict the performance of the Yucca Mountain site relative to the standards set by governing regulations and criteria, there must be adequate information regarding the properties and characteristics of the geologic system and the engineered systems used to operate the repository. This information includes data essential to:

- Predict the response of the geologic system to the construction and operation of the repository

- Predict the performance of the engineered materials under the loading and environmental conditions of the repository

During repository operation, the performance of the repository must be monitored to ensure that the natural and engineered systems perform according to the established design and performance limits. The information required to meet these objectives consists of measurements and observations of the response of the engineered materials within the repository and of the geologic system surrounding the repository during repository operation.

The data listed above can be obtained in several ways; the specific form of data depends on the application requirements in the design and subsequent analysis. The data requirements and required accuracy and resolution will also be different for each stage of repository operation and decommissioning. 
These data will ultimately be used in a deterministic approach to evaluate the repository, using computerized numerical techniques capable of modeling the coupled hydrologic, thermal, and mechanical properties of the rock and the response of the integrated systems to the loads imposed by the construction and operation of the repository. Numerical techniques, currently under development, permit such systems to be analyzed in an uncoupled fashion by separating the problem into its thermomechanical and hydrothermal components, and by using simplified assumptions regarding the properties of the rock mass and the rock support systems.

Given the limitations of both empirical and analytical methods, the confirmatory testing at the repository depth will be based on a synthesis of both techniques to measure displacement, stress, temperature, and hydraulic heads and gradients. The principal geotechnical parameters that must be measured by this in-situ testing are:

- Intra-flow stratigraphy and lithology of the repository horizon

- Virgin in-situ stress

- Virgin temperature of the rock mass

- Deformational properties of the rock mass (including the effects of temperature change)

- Geometric, strength, and hydrologic characteristics of the system of joints and fractures in the rock mass

- Thermal properties of the rock mass

- Effects of temperature change on the stability of the rock mass

- Permeability of the rock mass (including the effects of changes in stress and temperature)

- Hydraulic heads and gradients in and around the repository horizon

- Characteristics of the disturbed rock zone produced in the walls of the openings as a result of excavation

These parameters will be derived by synthesizing data obtained from:

- Point measurements within boreholes drilled from observation drifts

- Other underground observations, tests, and measurements

- Laboratory testing

The data obtained from in-situ measurements will primarily serve the important function of validating and calibrating the analytical models and computer codes that will be used to evaluate the repository. Data obtained in compliance with the PC commitments will be compared against 
predictions pertinent to those measurements and to support evaluations necessary to provide reasonable assurance that the repository will perform as predicted.

Implementation of a systematic data acquisition strategy calls for a number of decisions concerning the general methodologies to be used for data acquisition, the stage of repository operation, and the manner in which the data are to be used. In addition, these decisions require consideration of such factors as schedule and budget constraints and the degree of technical conservatism adopted for design and performance assessment. The current phase of the Yucca Mountain program is too early to finalize these types of decisions. The basic strategy, which will be enhanced in the years to come, is that in-situ data will be required to comply with regulatory commitments in support of the reasonable assurance argument for postclosure safety.

\subsection{IN-SITU METHODS FOR REPOSITORY DATA ACQUISITION}

In the following subsections, data acquisition methods are discussed in detail. The discussions include a description of advantages, limitations, and recommendations for the selection of appropriate methods and procedures for repository use. The data acquisition methods consist of:

- Seismic measurements

- Rock mass hydrologic properties

- Rock mass pneumatic properties

- Rock mass deformability

- In-situ stress

- Stress change

Rock mass strength

- Temperature measurements

In many cases specific tests and conditions for which a procedure will be employed remain undefined. When detailed test plans are developed, the ranges of the instruments will be identified. In most of the other cases, ranges and sensitivities cannot be established until the instruments are in place.

The resultant accuracy of the instrument system depends on the required instrument algorithm as well as the stability of the components under the environmental conditions. The overall system accuracy will be significantly affected by factors such as deviations of rock mass behavior from idealized behavior and the general ease and accuracy of installation and maintenance procedures.

\subsubsection{Seismic Measurements}

The location and magnitude of seismic events can be determined from the existing network of surface and subsurface seismograph stations. Seismic monitoring is already underway in the Exploratory Studies Facility (ESF) under the historical and current seismicity field work package (CRWMS M\&O 1997, p. 23). Any future work will be a continuation of this program. A ground motion station is currently in place in one of the Exploratory Studies Facility alcoves. 
Strong-motion monitoring can be used to measure the response of the subsurface facility to ground shaking. Although measurements can be used to validate seismic design assumptions, the most important benefit is to guide decisions on inspection and repair of the subsurface facility after it has been subjected to a seismic event.

Instruments for strong-motion monitoring are normally called strong-motion accelerographs or seismographs. The key element of the instrument is an accelerometer, which can be thought of as a mass suspended in a case. The case itself would be securely anchored to the tunnel wall or in a borehole for subsurface installations. During an earthquake, relative motion between the mass and the case provides an electrical signal proportional to either the acceleration or velocity of the ground motion (Dunnicliff 1988, section 21.3.3). These seismographs also contain signal amplifiers to allow the electrical signal to be transmitted to a remote location where the data can be interpolated.

\subsubsection{Rock Mass Hydrologic Properties}

Hydrologic data are necessary to assess the waste isolation potential of the repository horizon and rock units lying above the horizon. Essential data for this evaluation are hydraulic heads, gradients, and flow rates (see RKE/PB 1984, p. 3-20). Values for hydraulic conductivity (permeability) are also determined from these measurements. Data on the effective porosity and dispersivity of certain rock zones and the determination of specific storage are also necessary.

The transmissivity of a stratum is related to the hydraulic conductivity and the dimension of the stratum. To assess the velocity of water flow through the rock mass, parameters such as dispersivity and effective porosity need to be measured.

The permeability or hydraulic conductivity relates the water flow rate to the pressure gradient, which is defined by differences in hydraulic heads. Specific storage is the volume of water received from or added to a unit thickness of saturated rock per unit surface area and per unit change in hydraulic head. This parameter is important for transient flow analysis.

The following procedures can be used for determining the rock mass hydrologic properties:

- Constant head injection test

- Cross-hole test

- Constant drawdown test

- Constant discharge test

- Tracer Tests

- Seepage Measurements

The following sections briefly describe the procedures identified above. The hydrologic properties to be obtained by conducting the tests discussed in sections 6.4.2.1 through 6.4.2.4 include:

- Fluid inflow rate

- Hydraulic head and gradient 
- Hydraulic conductivity

- Specific storage

\subsubsection{Constant Head Injection Test}

The constant head injection test consists of pumping water into a borehole at a constant pressure for a given time and monitoring the injection rate (RKE/PB 1984, p. 4-81). This test is conducted in a flow interior zone of low hydraulic conductivity.

The general test procedure is as follows:

1. Achieve a hydrostatic head of an expected value (inject the water if necessary)

2. Allow the pressurized system to attain equilibrium or a pressure trend

3. Set up the injection manifold system

4. Inject gas into a water-filled tank of the manifold to achieve the preselected pressure steps above lithostatic pressure and monitor the injection rate

5. Maintain each pressure step until a steady-state flow is achieved or for a predetermined time interval

6. Repeat steps 4 through 5 three or four times

7. Record the discharge versus time, and pressure versus time data

8. Reduce the data and apply transient or steady-state solution as appropriate

\subsubsection{Cross-hole Test}

The cross-hole test consists of injecting or withdrawing water from the borehole and monitoring the effects in a nearby observation well (RKE/PB 1984, p. 4-81, 4-82). The injection mode is recommended because of the low natural gradient anticipated for the site. This test is conducted in a zone of low hydraulic conductivity.

The general test procedure is as follows:

1. Achieve a hydrostatic head of an expected value (inject the water if necessary)

2. Allow the pressurized system to attain equilibrium or a pressure trend

3. Set up the injection manifold system

4. Inject gas into water-filled tanks or manifolds to achieve the preselected pressure pulses in straddled interval of injection boreholes and monitor the injection rate 
5. Monitor the pressure decay in the injection hole and pressure response in the packed-off intervals of nearby observation holes

6. Maintain each pressure step until a steady-state flow is achieved and pressure responses are recorded in the observation holes

7. Repeat steps 4 through 6 several times

8. Record the injection versus time, and pressure versus time data

9. Reduce the data and apply transient or steady-state solution as appropriate

\subsubsection{Constant Drawdown Test}

The constant drawdown test consists of installing a suitable flowmeter at a borehole, monitoring the inflow rate for a given period of time, and then closing the flow and monitoring pressure recovery (RKE/PB 1984, p. 4-82, 4-83). This test is conducted in a zone of high hydraulic conductivity.

The general test procedure is:

1. Install flowmeter outside a high pressure gate valve

2. Open the gate valve and let flow for six to eight hours; monitor the flow rate drop as a function of time

3. Close the system and monitor the pressure recovery with time

4. Reduce the data

\subsubsection{Constant Discharge Test}

The constant discharge test consists of obtaining a constant inflow rate by adjusting a valve ( $\mathrm{RKE} / \mathrm{PB} 1984$, p. 4-83, 4-84). This constant discharge is allowed to flow for a specified period of time and then the valve is closed and the pressure build-up is monitored. This test is conducted in a zone of high hydraulic conductivity.

The general test procedure is:

1. Open a high pressure gate valve and adjust with time to maintain a constant discharge rate

2. Maintain the discharge for six to eight hours, though the exact time will be a function of the transmissivity of the rock

3. Close the valve and monitor the pressure recovery 
4. Reduce the data

\subsubsection{Tracer Tests}

Tracer tests are used to determine effective porosity and dispersivity (RKE/PB 1984, p. 4-96, 4100, 4-101). The following sections describe some of the more commonly used tracer tests.

Radial Flow Method for Multiple Boreholes - For this method, a tracer is introduced at a central well from which an artificial radial flow field has been established by fluid injection. Concentrations are measured at observation wells within the radius of influence of the injection mound. Multiple well injection tests have been used to determine effective porosity, dispersivity, and retardation. A large number of observation wells are normally required to obtain meaningful estimates of effective porosity due to the typically irregular shape of the displaced water volume. Conditions influencing the borehole layout include scale of the dispersion parameters measured. The scale is a function of the distance between the injection and observation wells.

Point Dilution Method for Single Boreholes - The borehole dilution method measures groundwater velocities. This technique involves injecting a tracer into a borehole and monitoring the decrease in concentration as natural flow moves the tracer into the surrounding rock. Borehole dilution tests have been used to measure groundwater velocity and vertical flow in boreholes. This technique is also useful for identifying high and low transmissive zones from a well.

Similar techniques include the injection-withdrawal method for a single borehole and the natural gradient injection method for multiple boreholes. The applicability of all three methods to obtain the hydrologic characterization of flow interiors is limited due to the low natural gradient and low transmissivity of the flow interiors at the site.

Injection-Withdrawal (Recirculation) Method for Two-Well System - In this test, water is pumped from one well and injected in a second, thus developing the maximum possible gradient between the two wells. This is the most commonly applied technique and has the greatest chance of success where wells are great distances apart or when the probability of tracer interception would otherwise be very low. This technique is commonly used for measurements of effective porosity and dispersivity, although it is relatively insensitive to variations in dispersivity. The overall effects of tracer dilution are minimized by a continuous injection of tracer for extended periods of time. During a single test, it is possible for a tracer to make more than one circuit through the system. Consequently, tracers detectable at extremely low concentrations are not required. The primary disadvantage of this method is the time required for completion of the test.

Convergent Flow Test for Multiple Boreholes - For this test, groundwater is pumped from a single well, creating a flow system in which the flow lines converge on a single point. This technique is useful for determining effective porosity and dispersivity. Measurement of both dispersivity and effective porosity are aided by tracer observation at points arranged in a line across the flow system, thus defining the width of the tracer plume. The principal difficulty 
associated with the convergent test is that of tracer dilution. Only a small amount of tracer can be injected because it is normally added in a single instantaneous pulse. The tracer is diluted at an exponentially decreasing rate and is further diluted at the pumping station by mixing with the unlabeled water converging there.

Evaluation of Tracer Tests - The tracer test most likely to succeed at the repository horizon level is the radial flow technique for multiple boreholes. This test is preferred over the other methods for the reasons discussed within each subsection. In summary, the other techniques are usually associated with one or more of the following disadvantages:

- Travel times are too long for natural gradients

- Insufficient water is expected in the candidate horizon interior to sustain the flow rate

- Low-transmissivity rock does not permit fluid recirculation

The radial flow method is recommended for the flow interior, tracer-type testing from the boreholes drilled at the repository horizon.

\subsubsection{Seepage Measurements}

A passive system to detect direct seepage from the host rock is currently in place and operating during the site characterization period. Seepage collection mats that are $\mathrm{pH}$ (hydrogen ion concentration) sensitive have been installed in Alcove 7 that is isolated from the effects of the ventilation system. Although no direct evidence of seepage has currently been found, this passive system will continue to be monitored to support PC activities. In addition to this passive system, heat dissipation probes and time domain reflectometry will be used to more actively determine whether seepage is likely to occur prior to and during thermal loading of the repository. The use of these passive and active methods coupled with the locations of the future alcoves will confirm that seepage is occurring within the expected bounds and assumptions important to postclosure performance.

In-situ monitoring of water seepage will require short alcoves, which are to be hermetically sealed from the ventilation system using bulkhead doors. The sealed alcoves will require access through the bulkheads to access the instrumentation installed in the isolated sections. Conceptually, the alcoves will be approximately 20 meters in total length, with an exterior area for staging entry into the isolated sections and housing data acquisition equipment.

\subsubsection{Rock Mass Pneumatic Properties}

Data gathered by means of air permeability tests provides an understanding of the conditions within the repository, specifically the potential pathways for gas flow. As the rock mass is heated during waste emplacement, water in the rock will vaporize, and the majority of fluid movement will presumably occur in the gas phase. Results obtained from the air permeability tests will provide an estimate of the three-dimensional, heterogeneous permeability structure and fracture connectivity in the rock mass of the repository. This information can provide input to a conceptual model and allow estimates of liquid, heat, and gas flow in the repository. 
Each borehole drilled for this purpose will contain a series of pneumatically inflated packers to allow various sections of the borehole to be isolated. Each interval (between packers) can be instrumented with relative humidity, temperature, and pressure transducers. Injection tubes will be installed in the intervals between the packers and in the interval past the end of the last packer. Dry, clean compressed air is regulated using mass flow controllers and is injected into the designated interval of the borehole, depending on which packers are inflated. The various sensors then monitor the response to the air injected into the intervals of the borehole.

Especially important to the successful interpretation of this type of test is knowledge of the location of fractures within the borehole. The best way to accomplish the mapping of the borehole interior is by initial inspection by means of a boroscope, which operates like a periscope, or by use of a borehole television camera. These instruments allow the borehole to be visually and accurately mapped and suitable zones identified for testing. The relationship of test zones to fracture densities is vital to data interpretation and is necessary for comparisons with other test boreholes.

\subsubsection{Rock Mass Deformability}

The following data acquisition procedures can be used for determining rock mass deformability at ambient temperature:

- Borehole jacking test

- Dilatometer test

- Shallow flat jack test

- Rigid plate jacking test

Each of these procedures are described herein, including a brief statement about the advantages and limitations of the procedure.

\subsubsection{Borehole Jacking Test}

The borehole jacking test for rock deformability entails applying a unidirectional load to opposite sides of a borehole via curved loading plates (ASTM D 4971-89, section 4). The load is applied using a hydraulic pressure system, and changes in borehole diameter are measured using electrical linear displacement transducers (refer to Figure 1). Load and diameter measurements are used to determine deformability by applying the theory of elasticity to the test boundary conditions. The way in which the borehole jacking test is used, that is, for absolute or relative values of deformability, requires particular corrections to be employed that are reliant on several factors. Principally, these factors include the magnitude of the rock modulus itself, anisotropy, and fracturing. This means that preliminary estimates are required to choose the proper correction procedure. 


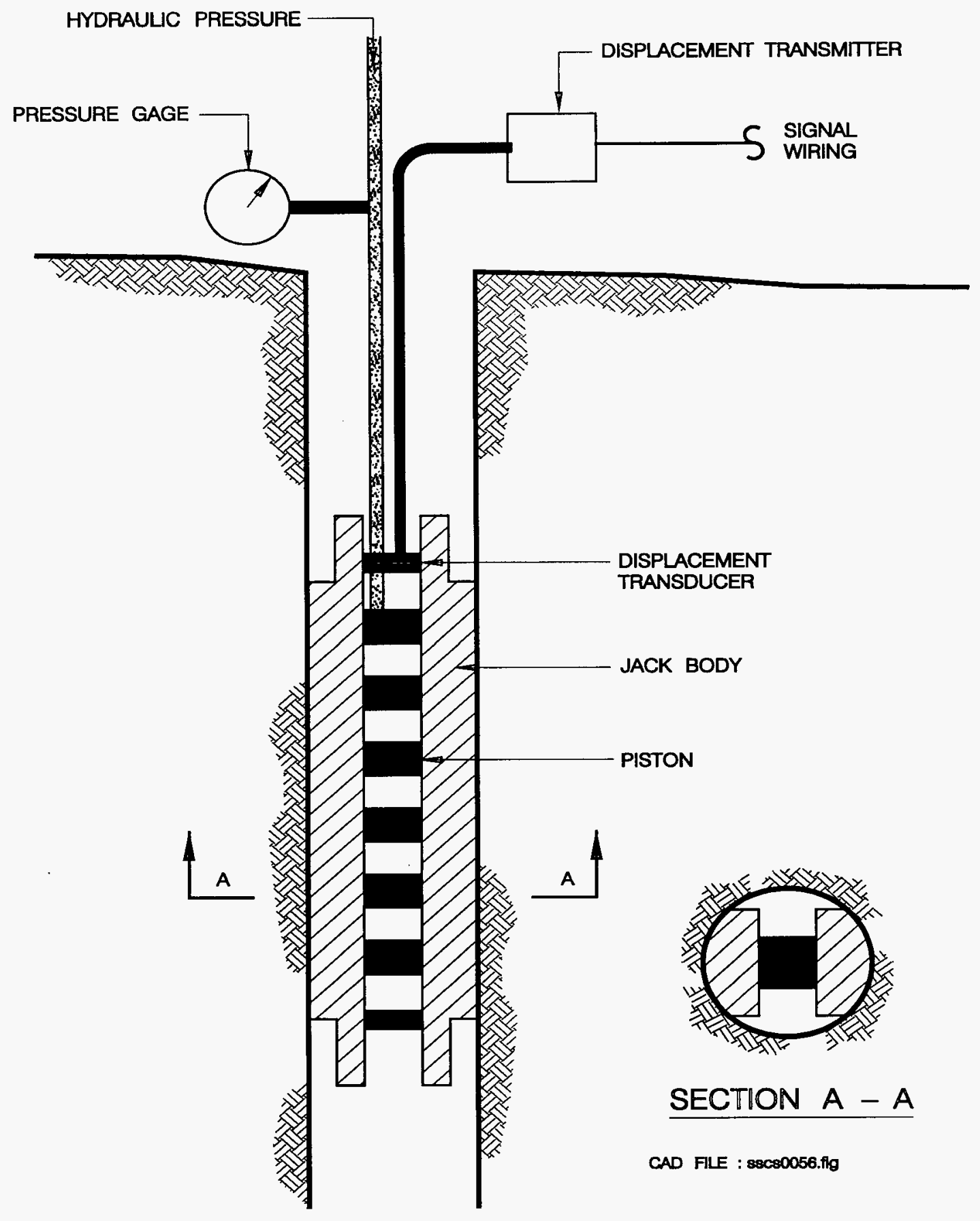

Figure 1 - Schematic of Borehole Jack Equipment 
Especially important to the successful application of linear elastic theory to the interpretation of this type of test is the location of the jack in an unfractured portion of the borehole. The best way to accomplish this is by initial inspection of the borehole wall by means of a boroscope, which operates like a periscope, or by use of a borehole television camera. The requirement that such an inspection be carried out is common to the operation of nearly all borehole instruments that react either passively or actively with the wall of the borehole.

The advantages of the borehole jacking test are:

- Borehole jacks provide a good index of rock quality, particularly in homogeneous "elastic" rock and on a site-specific basis.

- A large number of locations can be tested rapidly (this could be considered a disadvantage; the test is rapid and inexpensive and is often used without recognition of its limitations).

- Measurements at different locations, such as along a borehole, can be compared to determine variations in rock deformability. For example, the AZ may be identified by this means.

The limitations of the borehole jacking test are:

- The absolute rock mass deformability data scale is too small and the range of action is too limited.

- A strong dependance on the contact angle between platens and rock and on longitudinal flexure of platens is required, with corrective procedures uncertain.

- Results are stress (stress level affects jack/rock contact geometry) and path dependent.

\subsubsection{Dilatometer Test}

In the dilatometer test, a radial stress is applied to a section of borehole and the resulting deformation is measured (RKE/PB 1984, p. 4-8). Dilatometers are also referred to as earth pressure cells.

The test equipment consists of a cylindrical inflatable probe connected to a control unit for water pressure application. Deformation is determined from measurements of water volume or by using electrical linear displacement transducers in the probe; see Figure 2. The test procedure involves inflating the probe with water at increasing pressure increments and recording the resulting deformation (from changes in liquid volume) at various time intervals.

As mentioned above in the borehole jacking test section, a boroscope or borehole television camera is recommended as a means of mapping the location of fractures within the borehole. The relationship of test zones to fracture densities is vital to data interpretation and necessary for comparisons with other test boreholes. 


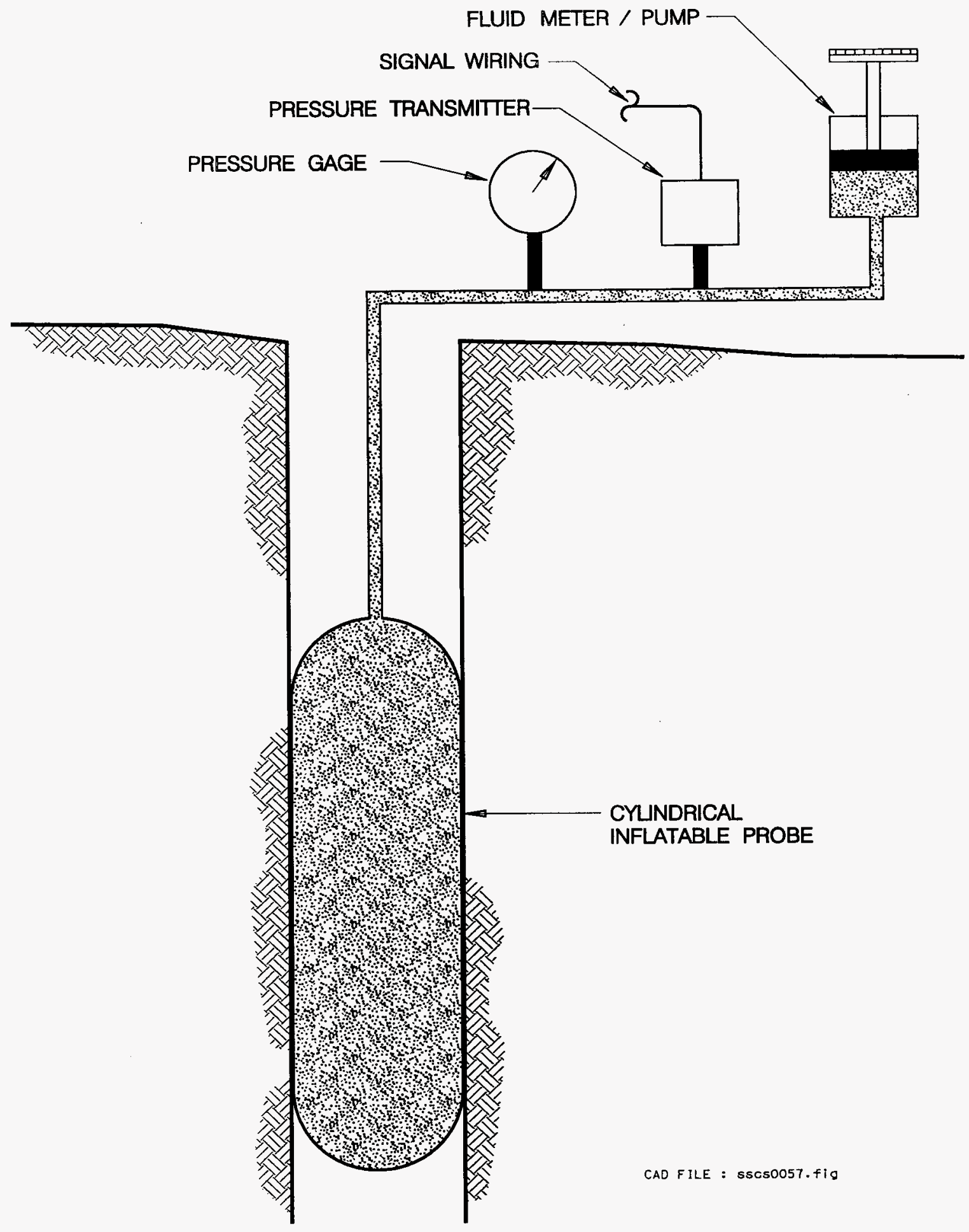

Figure 2 - Schematic of Dilatometer Equipment 
The advantages of the dilatometer test are:

- Dilatometers provide a good index of rock quality, particularly in homogeneous "elastic" rocks and on the basis of site-specific conditions.

- Numerous locations can be tested rapidly.

- Measurements at different locations, such as along a borehole, can be compared to determine variations in rock deformability. For example, the $\mathrm{AZ}$ may be identified by this means.

The principal limitation of the dilatometer test is that dilatometers should not be considered for generating absolute rock mass deformability data because their scale is too small and their range of action too limited, i.e., they provide a point measurement.

\subsubsection{Shallow Flat Jack Test}

A flat jack is composed of two metal plates welded together along their edges forming a void, which is filled with liquid and fitted with pressure regulation and monitoring capabilities (ASTM D 4729-87, section 3). The test procedure involves installing strain gauges on either side of the proposed slot in the rock, reading the gauges, cutting or drilling the slot, inserting the flat jack, and increasing jack pressure while reading the strain gauges at each pressure increment; see Figure 3. A plot of pressure versus strain yields deformability data. Strain gauges are usually mechanical or vibrating wire type. It is important to recognize that shallow flat jack measurements are made close to the wall of an underground opening, which may be within the zone of stress concentration surrounding the opening. If the opening has been excavated by blasting, the zone may also have been subject to the effects of blasting. Deformability data are likely to be affected by both of these factors. For these reasons, the conventional shallow test is not suitable for the determination of deformability at depth in a rock mass.

The primary advantage of the shallow flat jack test is that a relatively large zone of rock is tested.

The limitations of the shallow flat jack test are:

- The test can only be used to measure deformability of the rock mass adjacent to an exposed surface.

- Measurements of deformation in rock beneath the loaded area would be difficult to perform. 


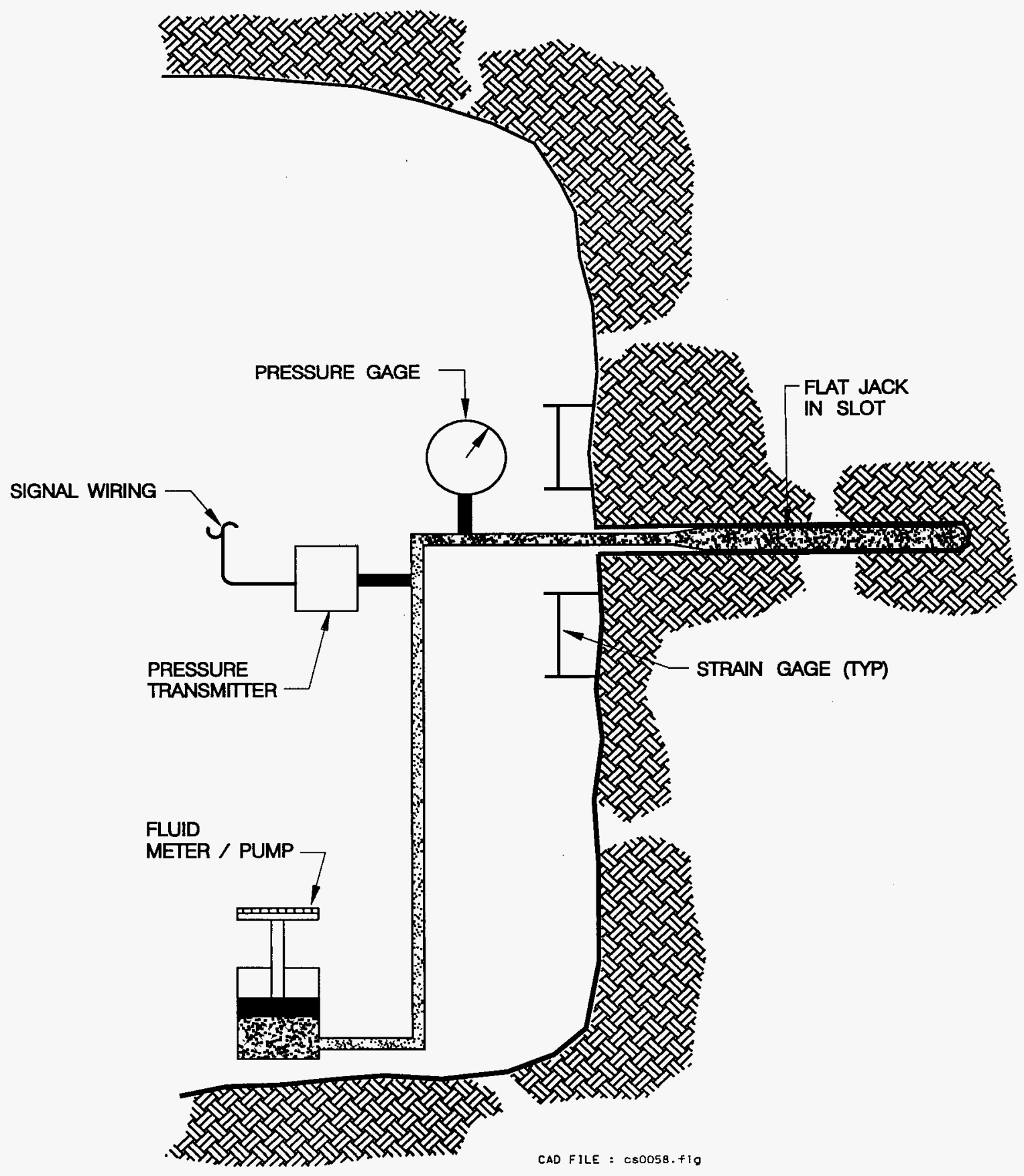

Figure 3 - Schematic of Flat Jack Test Equipment 


\subsubsection{Rigid Plate Jacking Test}

Rigid plate jacking tests, also referred to as plate loading tests, are used for determining rock deformability and consist of loading an exposed and well-prepared flat surface of rock and measuring the resulting deformation (ASTM D 4394-84, section 4). The load is normally applied to a rigid circular plate by hydraulic jacks, using the opposite wall of the excavated area as the fixed or anchored end. One setup is frequently used to test both walls; see Figure 4. The load is normally measured by interposing a circular flat jack between the rigid circular plate and the prepared surface and measuring the passive hydraulic pressure in the flat jack. Deformation is measured at various points below the plate using borehole extensometers (see section 6.5.2).

The advantages of the rigid plate jacking test are:

- A relatively large zone of rock is tested.

- Measurements of deformation within the rock mass can be carried out using borehole extensometers.

The limitations of the rigid plate jacking test are that in near surface rock, the test stress is sufficiently large and the resulting deformations are measurable using high precision electrical extensometers. However, the measured deformability is not representative of the rock mass due to stress concentration and blast damage. Beyond approximately 1.5 meters deep, the test stress is much smaller and the deformation due to blast damage is less, which results in deformations too small to measure with certainty. However, this limitation can be minimized by trimming the test location using controlled excavation methods, such as water jetting or other methods of line drilling or presplitting. Another limitation is the expense of performing such tests.

\subsubsection{Recommendations for Determining Rock Mass Deformability}

Test locations should be representative of typical in-situ conditions. In order to adequately sample the rock mass, it is necessary to test at a representative scale, which is determined by the fracture spacing. Rock is a naturally variable material, requiring sampling at numerous locations according to the degree of variability expected.

Scale problems create severe limitations for borehole jack and dilatometer tests and both are often used without adequate recognition of this fact. Borehole jacks are further limited by the strong dependence on the contact angle between platens and rock, and by longitudinal flexure of the platens (ASTM D 4971-89, section 6.3.1 \& 6.3.2): The primary application of borehole jacks and dilatometers is for index tests; however, their use even for this purpose is limited where the rock is highly fractured and the instrument scale does not model prototype conditions. 




Figure 4 - Schematic of Rigid Plate Jacking Test Equipment 
The shallow flat jack test is severely limited by the fact that only rock immediately adjacent to an opening can be tested, which has been disturbed by the excavation of the opening and subjected to induced stress. However, development of deep-slot flat jack testing procedures would overcome this problem, resulting in an economical procedure for determining deformability of undisturbed rock mass.

The rigid plate jacking test provides viable data for deformability of the disturbed rock zone and, provided that test locations are carefully trimmed using controlled excavation methods, of undisturbed rock mass. For these reasons, use of the rigid plate jacking test should be considered.

\subsubsection{In-Situ Stress}

Rock is rigid and permits the transfer and storage of very high stress concentrations. Geologic engineers like to distinguish between in-situ stress created by geologic processes and induced stresses caused by excavation or other man-induced actions. The in-situ stresses were first established by the continental drift, perhaps a million years ago. These initial stresses have since been modified by the decomposition and erosion of the geologic material. In the past, many locations on the surface of the earth were covered by several miles of soil, rock, or ice. Weathering and erosion over the millions of years have removed this overburden. However, the horizontal stresses existing in rocks that were once deeply buried may not be entirely relieved by the erosion.

When an excavation is made in rock, some of the stresses originally carried by the excavated material are transferred to the rock that remains in place. Stress levels in tunnels can be amplified to several times their initial in-situ values (Dunnicliff 1988, section 2.2.4).

The following data acquisition procedures can be used for determining in-situ stress:

- Shallow flat jack test

- USBM (United States Bureau of Mines) gauge with overcoring

- Door-stopper biaxial strain cell with overcoring

- CSIRO (Commonwealth Scientific and Industrial Research Organization) triaxial strain cell with overcoring

- Hydraulic fracturing

The following descriptions of these procedures include a brief description of other, less applicable methods for determining in-situ stress. The procedures fall into three general categories, depending on the location of the rock subjected to a test: (1) tests performed in rock immediately adjacent to an exposed surface, (2) tests performed in shallow boreholes, (3) tests performed in deep boreholes. 


\subsubsection{Shallow Flat Jack Test}

The basic shallow flat jack procedure is described in Section 6.4.4.3. Jack pressure is increased until strain gauge readings are restored to their original values. This pressure is referred to as the "cancellation pressure" and is related to the stress existing in the rock prior to cutting the slot. It is important to recognize that flat jack measurements are made close to the wall of an underground opening, which may be within the zone of stress concentration created by excavation and blasting effects. Knowledge of the induced stress field around the excavation is required in order to convert the measured stress (or induced stress) to the in-situ stress. Such stress fields are very difficult to predict in fractured rock; therefore the test is not suitable for determining in-situ stress.

The advantages of the shallow flat jack test are:

- Rugged and stable equipment

- No need to determine deformability

The limitations of the shallow flat jack test are:

- The test can only be used to measure stress adjacent to an exposed surface, i.e., not virgin in-situ stress.

- The test can only be used to measure compressive stress.

\subsubsection{USBM Gauge With Overcoring}

The USBM borehole deformation gauge is designed to measure diametrical changes in a small diameter borehole, which allows for determination of in-situ stress, by use of an overcoring procedure (ASTM D 4623-96, section 4). The test entails a series of steps, which are illustrated in Figure 5. A large diameter hole is drilled at the test location followed by drilling a short concentric smaller hole. The gauge is inserted within the smaller hole and overcored by advancing the large hole to a depth beyond the gauge, with the gauge cable passing through the drill rods and a special drill swivel so that gauge readings can be made during drilling. The gauge contains strain gauge sensors for measuring diametrical changes on three planes 60 degrees apart. The rock around the gauge is, therefore, stress relieved upon coring and, if in-situ stress is compressive, the gauge indicates increasing diameters as overcoring advances. The donut-shaped core is withdrawn, inserted within a biaxial pressure chamber designed to apply hydraulic pressure to the outside of the core, and the gauge inserted in the central hole at the same depth and orientation as in the borehole. Core deformability is determined by applying hydraulic pressure and measuring the central hole diameter changes. These deformability characteristics, together with the diameter changes during overcoring, provide data for determining stress relief during overcoring. The magnitude of stress relief is assumed to be equal and opposite in sign to the in-situ stress in the plane normal to the axis of the borehole. 
1.

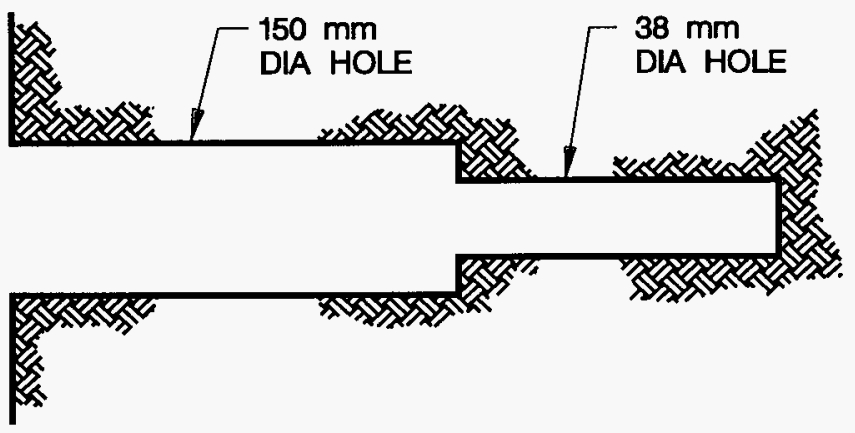

2.

GAGE CABLE



3.
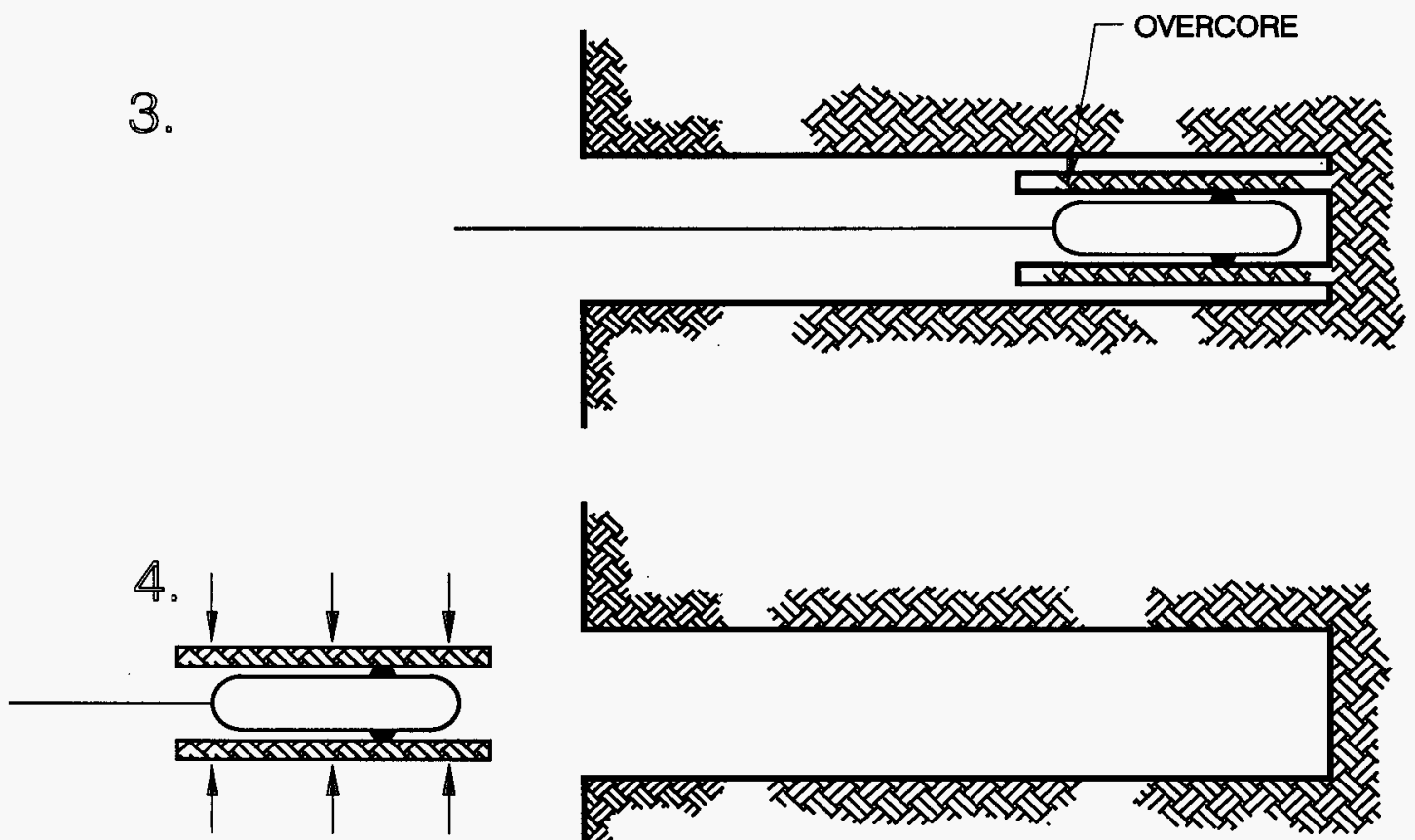

TEST FOR DEFORMABILTY

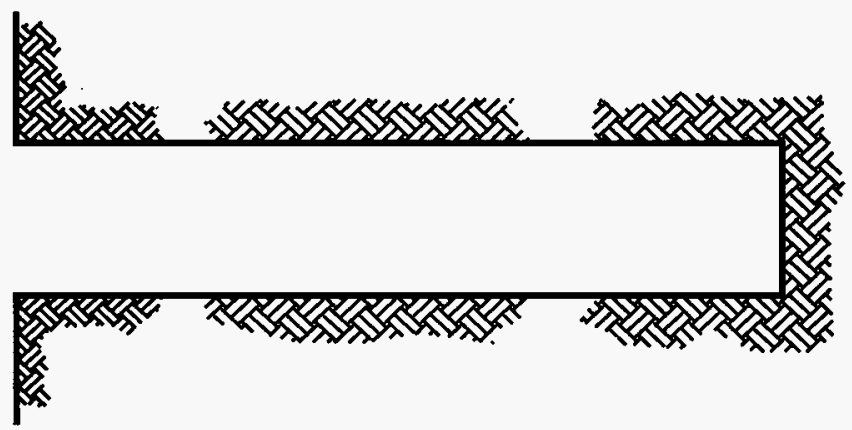

Figure 5 - Test Sequence for Determination of In-situ Stress Utilizing the USBM Borehole Deformation Gauge 
Several improvements have been made to this test technique, including centering the $38-\mathrm{mm}$ borehole by attaching the small core barrel to an assembly fitted to the bit thread on the large core barrel, and use of a $150 \mathrm{~mm}$ by $197 \mathrm{~mm}$ double-tube core barrel to minimize core breakage (RKE/PB 1984, p. 4-36). The barrel is turned using flush joint casing rather than drill rods so that the borehole deformation gauge can be inserted after the overcoring tools are in place. Ball bearing stabilizers can be used on the casing to facilitate core recovery.

The advantages of the USBM gauge are:

- The gauge is reusable.

- Gluing or grouting processes are not involved.

- Deformation measurements are made repeatedly during overcoring, thus increasing the reliability of strain relief data.

- Moderate gauge length (borehole diameter).

- There is a long history of the gauges use.

The limitations of the USBM gauge are:

- The test scale is small.

- There is a need to assume linear-elastic behavior for data reduction and interpretation of stress concentrations around the borehole.

- The gauge requires a zone giving an unbroken core at least $200 \mathrm{~mm}$ long (RKE/PB 1984, p. 4-37).

- The gauge can be disturbed by vibrational effects during overcoring, resulting in false measurements.

- The gauge can be damaged if the core breaks.

- Three nonparallel boreholes are required for determining three dimensional stress states.

- Requires a large diameter overcore drill ( 150 mm) (RKE/PB 1984, p. 4-37).

- Practical borehole depth limit is 30 to 60 meters (RKE/PB 1984, p. 4-38).

- A need to minimize temperature differences between drilling water and the rock to avoid temperature-induced errors. 
The requirement for an unbroken core at least $200 \mathrm{~mm}$ long can be alleviated somewhat by use of a "reverse case" gauge, in which the positions of deformation measuring points and centralizing springs are reversed. Stress relief at the measuring point therefore occurs early during overcore drilling. The reverse case gauge is also preferred in highly fractured rock to reduce vibrational effects during overcoring. However, the data needs to be adjusted to correct for concentrations of stress resulting from proximity to the $150-\mathrm{mm}$ borehole (RKE/PB 1984, $\mathrm{p}$. 4-38). If the length of the recovered core is less than $200-\mathrm{mm}$, deformability for strainlstress conversion cannot be determined from the conventional biaxial chamber test, and an alternative method is required. This approach presumes an exact knowledge of the fracture locations prior to overcoring and therefore will require accurate drilling methods and the use of a boroscope or borehole TV camera. The success of this method depends in large part on the presence of zones of intact rock, sufficiently long for operation.

\subsubsection{Doorstopper Biaxial Strain Cell With Overcoring}

The CSIR "doorstopper" gauge was developed in South Africa for measuring in-situ stress in a single plane (RKE/PB 1984, p. 4-39). The name "doorstopper" was given to the cell because of its resemblance in color, size, and shape (in its early phase) to the red rubber cylindrical blocks commonly used as doorstops in homes. The cell consists of a cylindrical rubber casting with a rosette of four strain gauges mounted on one end. In this test, a $60-\mathrm{mm}$ diameter hole is drilled at the test location, the end is drilled and polished flat with special bits, the cell is cemented to the end, and initial strain gauge readings are made. The strain gauge cables are disconnected from the cell, the cell is overcored with a $60 \mathrm{~mm}$ diameter borehole, the core and cell are withdrawn, the cables are reconnected, and final strain gauge readings are made. The stressrelieved core, with the cell attached, is then inserted within a borehole simulator, which allows application of two radial hydraulic pressures at right angles to each other. The orientation of secondary principal stress is determined directly from the field strain relief data. The core is positioned in the simulator so that radial hydraulic pressure is applied in the same orientation, and pressure is applied to restore the strain readings to those before overcoring. The applied pressure, together with a correction for stress concentrations due to borehole end effects, are used to calculate in-situ stress in the plane perpendicular to the axis of the borehole.

The advantages of the doorstopper gauge are:

- The cell is unlikely to be disturbed by overcoring.

- Strain readings are made repeatedly while overcoring, which increases reliability of strain relief data.

- This gauge requires only a short length of unbroken core.

- The cell is overcored with a $60 \mathrm{~mm}$ borehole

- An underwater adhesive has been used with satisfactory results.

The limitations of the doorstopper gauge are: 
- The test scale is limited to the size of the borehole.

- The need to assume linear-elastic behavior for data reduction and interpretation of stress concentrations around the borehole; data must be adjusted for stress concentration at end of borehole.

- Axial stresses, if present, can cause large errors.

- The end of hole requires polishing.

- The practical borehole depth limit with attached signal cable from the cell is 30 to 60 meters.

- Three nonparallel boreholes are required for determining three-dimensional stress states.

- The cell is not re-usable.

- There is a need to minimize temperature differences between drilling water and the rock to avoid temperature-induced errors.

\subsubsection{CSIRO Triaxial Strain Cell With Overcoring}

The CSIRO "hollow inclusion stress cell" developed in Australia consists of three strain gauge rosettes, each with three gauges oriented at 120 degrees along the circumference of an epoxy pipe and sealed with a protective resin to prevent ingress of drilling water into the electrical system (RKE/PB 1984, p. 4-48). A 38-mm diameter hole is drilled to the test location and then overcored, usually with a 150-mm core drill, while strain gauge readings are made; the core and cell are then withdrawn and tested in a biaxial pressure chamber. The biaxial chamber test provides deformability characteristics, including Poisson's ratio, necessary for reduction of the strains measured during overcoring into magnitude and orientation of principal stresses. The presence of the resin must be taken into account in the data reduction, since it forms an annulus between the strain gauges and the rock.

When using an overcoring technique, any temperature difference between the rock and the drilling water will create thermally induced strains and for all techniques, the two temperatures should be maintained as close as possible by cooling or heating the drilling water if necessary. Laboratory tests have indicated that when temperatures of the rock and the drilling water are not equal, overcoring a CSIRO cell results in ninety-five percent complete stress relief at the time when the temperature change at the position of the strain gauges in the cell is only approximately fifteen percent complete. By controlling drilling water temperature and ignoring strain data after most of the stress relief has occurred, the CSIRO cell can be used to obtain usable in-situ stress data, provided that appropriate cements are used and that the test is performed in an adequately long intact rock zone. One major limitation of its use appears to be when the fracture frequency of the rock is greater than 20 fractures/meter. The cell requires an unbroken core of at least 125 
to $150 \mathrm{~mm}$ and according to the manufacturer, unsuitable measurement sites are those where intact cores are consistently less than $300 \mathrm{~mm}$ long.

Advantages of the CSIRO cell are:

- Three-dimensional stress states can be determined in a single borehole.

- The cell is unlikely to be disturbed by overcoring drilling.

- Deformation measurements are made repeatedly while overcoring, thereby increasing reliability of strain relief data.

- Multiple gaging provides built-in check on measurements.

Limitations of the CSIRO cell are:

- Test scale is limited to the size of the borehole.

- The need to assume linear elastic behavior for data reduction and interpretation of stress concentrations around the borehole.

- The cell requires a zone giving an unbroken core longer than the cell (125 to $150 \mathrm{~mm}$ ) and preferably at least $300 \mathrm{~mm}$ long.

- There can be cementing problems if the borehole is wet.

- The practical borehole depth limit is 30 to 60 meters.

- The cell is not reusable

- There is a need to minimize the temperature differences between drilling water and rock to avoid temperature-induced errors.

\subsubsection{Hydraulic Fracturing}

An in-situ stress determination by hydraulic fracturing is typically performed at some location along the length of a 76-mm diameter borehole (ASTM D 4645-87, section 3). At the location where a measurement is desired, an interval (typically 3 to 4 meters long) is isolated by inflatable rubber packers. A hydraulic fluid such as water is used to pressurize the rock at this interval. At a critical (called breakdown) pressure, the rock develops a tensile fracture. This fracture can be extended away from the hole by continued pumping. When the pump is shut off with the hydraulic circuit kept closed, a "shut-in" pressure is recorded. This is the pressure necessary to keep the fracture open. In-situ stress magnitudes are determined from the breakdown and shut-in pressure. An impression packer is used to determine the orientation and inclination of the hydrofracture, which develops along a plane perpendicular to the direction of the least principal stress (least compressive). 
A basic assumption of the hydrofracturing method is that the borehole is aligned parallel to a principal stress direction. In the case of a vertical hole, this parallel stress component is assumed to be equal to the weight of the overburden. This assumption, along with the assumptions of linear elastic rock behavior, homogeneous conditions, and isotropic properties, allows estimation of the local stress tensor.

The advantages of the hydrofracturing method are:

- The test can be performed at great depth.

- The minimum principal stress is measured directly (no strain-to-stress conversion).

- This method can be used as a routine test to determine stress gradients.

- This method tests a larger volume of rock than overcoring methods.

One limitation is that although the minimum principal stress is obtained directly, several assumptions are required to obtain the other principal stresses. The assumptions involve pore pressure considerations, the tensile strength of the rock, and the assumption of isotropic, linear elastic rock.

Other limitations of the hydrofracturing method are:

- Measurements must be made in an unfractured section of the rock mass (unless stress across a defined fracture or bedding plane is required).

- An impression or other record of the fracture must be taken after fracturing.

- The most critical stress component in underground excavation design is the maximum stress, which is determined indirectly, thereby rendering the method questionable.

- For deep applications, boreholes are usually vertical and this may bias the initiation of fractures and the test results in general.

Ideally, to be suitable for determining in-situ stress, a packed-off interval should be free from fractures. The degree to which this condition will affect the test results (i.e., induced-fracture orientation, breakdown pressure, shut-in pressure) is unknown; however, if fracturing is found to be randomly oriented, the overall control of induced-fracture orientation should be lessened.

When determining the stress tensor, the hydrofracturing borehole must be oriented parallel to a principal stress direction. This assumption is reasonable for a deep vertical borehole, but less so for a short vertical hole from an opening, or for a horizontal hole. A long horizontal borehole will only be suitable for assessing stress variability by hydrofracturing if the assumption can be made that a principal stress direction parallels the hole and maintains a constant orientation along the length of the hole (RKE/PB 1984, p. 4-55). 


\subsubsection{Recommended Procedures for Determination of In-Situ Stress}

When planning procedures for in-situ stress measurements, it is important to recognize that the purpose is to determine the initial state of stress in the rock prior to excavation. Any opening made to determine stress will cause a fundamental change in the original stress conditions, a change that is often difficult to predict with certainty. The procedures that should be followed when measuring stress include:

- Utilize excavation techniques that minimize disturbance and, therefore, avoid significant inelastic behavior.

- Select points at the opening where the rock is sound and its behavior will not be influenced by geologic structure.

- Complete relief of the stress on the initial opening by measuring the strain change; the strain change must be sufficient to allow for accurate measurement.

- Determine the elastic material properties of the rock.

- Determine the initial stress state from the measured strains.

Locations for measurement should be selected with great care. The initial opening in the rock, the surface strains of which will be observed, must be smooth and free of defects. The rock in which the opening is made must be sufficiently competent to ensure that the opening will behave elastically and that localized failure or non-elastic behavior of the rock surface will not occur. If these conditions are followed, the stress concentrations around an opening can be predicted and the measured surface strain evaluated to provide an assessment of the virgin stress field. Strain on the opening surface must be measured at locations where the deformability of the strain measuring scale is representative of the rock mass as a whole. The strain measurement location must, therefore, be devoid of significant rock fractures, inclusions, or jointing.

The following methods appear worthy of consideration:

- Miniature USBM gauge with overcoring

- Doorstopper gauge with overcoring

- Hydraulic fracturing

The only method available for testing at depths greater than 30 or 60 meters in boreholes is the hydraulic fracture test.

The miniature USBM gauge and the doorstopper gauge are also both viable test methods. There will always be an advantage to using more than one type of test method to achieve a degree of redundancy in a measurement program.

The absolute accuracy of any stress measurement system is limited mainly by the difficulty of adequately describing the behavioral model that controls the measurement process. For the 
overcoring technique, the general limitations are governed by the need to convert strain to stress and the simplifying assumptions of linear elasticity. Although compensations can be made for certain effects by directly testing the overcore and simulating the in-situ stress changes, it is difficult to see how overall accuracies much better than \pm 25 percent can be obtained with one technique, even though greater accuracies may be possible at individual point determinations.

\subsubsection{Stress Change}

The following data acquisition procedures can be used for determining stress change:

- Borehole deformation gauge

- Shallow flat jack

- Borehole pressure cells

- Rigid inclusion stressmeter

- Borehole strain cells

- Photoelastic stressmeter

These procedures are, in turn, described below, in each case with a brief statement of their advantages and limitations.

\subsubsection{Borehole Deformation Gauge}

The USBM borehole deformation gauge as described in Section 6.4.5.2 has been used for monitoring borehole deformation over a period of several months.

The primary advantages of the USBM gauge are:

- The gauge is reusable.

- Gluing or grouting processes are not involved in the installation of the gauge.

The limitations of the gauge are:

- The gauge provides only a point measurement.

- The gauge is not proven for long-term monitoring at ambient or elevated temperatures.

- A deformability value is needed for the strain/stress conversion.

\subsubsection{Flat Jacks}

The shallow flat jack as described in Section 6.4.4.3 can be left in place for monitoring stress change.

Shallow flat jacks have the primary advantage of monitoring a significant zone of rock, rather than just a point measurement.

The limitations of the shallow flat jacks are: 
- Shallow flat jacks are limited to monitoring near the rock surface.

- Shallow flat jacks are not proven for monitoring at elevated temperatures.

\subsubsection{Borehole Pressure Cells (BPCs)}

The USBM cylindrical pressure cell (CPC) can be used for monitoring changes in rock stress at depths beyond the capability of flat jacks (RKE/PB 1984, p. 4-64). Such measurements are possible by closing a valve at the screw pump when the cell pressure is greater than the in-situ rock stress and allowing the system to stabilize. Any subsequent change in rock stress can be calculated from the measured change in cell pressure. The USBM BPC can also be used. The $\mathrm{BPC}$ is a small flat cell in which stress change in the plane of the BPC is determined as for the $\mathrm{CPC}$ using corrections for sensitivity to stress change parallel to the plane of the BPC.

The hydraulic pressure cells discussed here are best utilized in various combinations. For example, two of the flat BPCs should be installed in the same borehole, aligned adjacent to each other, and oriented at right angles to each other so that two components of the field stress change perpendicular to the borehole might be obtained. The CPC measures the sum of the components of stress change; locating a $\mathrm{BPC}$ adjacent to a $\mathrm{CPC}$ allows resolution of the components.

Experimental and field experience by the USBM shows that the BPC, especially, has the capability for monitoring stress change in hard rock. A typical sensitivity for a BPC in rock with a modulus of 70 Gigapascals (Gpa) is 0.15 Megapascals (MPa) hydraulic pressure change for a rock stress change of $1 \mathrm{MPa}$.

The advantage of the pressure cells is their simplicity and low cost.

The limitations of the pressure cells are that they provide only a point measurement and are unproven for monitoring at elevated temperatures.

\subsubsection{Rigid Inclusion Stressmeter}

The most commonly used rigid inclusion stressmeter is the vibrating wire stressmeter, which was developed for measuring stress change in underground coal mines (Dunnicliff 1988, section 11.4.1). The stressmeter consists of a thick-walled steel cylinder with a vibrating wire straingauge transducer mounted across a diameter at approximately mid-length of the stressmeter. The cylinder is typically installed within a $38-\mathrm{mm}$ diameter borehole using special setting tools, and is preloaded across a diameter with a wedge and platen. By calibration, changes in vibrating wire frequency are related to stress changes in the rock. Three gauges set at different angles to each other are required for a complete evaluation of changes in the stress field in the plane normal to the borehole axis. The stressmeter has proven reliable for ambient temperature applications in coal, for which it acts as a rigid inclusion and is quite insensitive to deformability. The stressmeter has also performed reliably at ambient temperature in hard rock, but is no longer a true rigid inclusion and, in this instance, requires calibration for deformability effects. However, the gauge readings remain highly dependent on contact geometry, initial preload, and deformability of the rock. 
The advantages of the rigid inclusion stressmeter are:

- The gauge is reusable.

- The gauge has performed well at ambient temperature in coal and hard rock.

The limitations of the rigid inclusion stressmeter are:

- The gauge provides only a point measurement.

- The gauge calibration depends on rock deformability, contact geometry, and initial preload.

- The gauge is not proven for monitoring at elevated temperatures.

\subsubsection{Borehole Inclusion Strain Cells}

Biaxial and triaxial strain cells could be considered for monitoring stress change. However, these cells have not been proven for long-term monitoring at ambient or elevated temperatures and satisfactory development is unlikely.

A new design would be required for a strain cell to suit the particular performance requirements of the repository. The basic element of the design would need to be a thin-walled cylindrical body of a noncreeping but relatively low modulus material that would be grouted in place to make an intimate welded bond with the borehole wall. Internal displacement or strains would be recorded with a biaxial or triaxial arrangement of sensors and these values would be calibrated to determine stress changes.

The advantages of this new design of strain cell would be:

- Low system stiffness would reduce bond stresses and creep.

- Triaxial stress changes would be monitored.

- The potential for operation at temperatures to $300{ }^{\circ} \mathrm{C}$, and in the presence of water and steam.

The limitations of the new design would be:

- The new design would depend on laboratory calibration in blocks of welded tuff.

- The new design would require a high temperature, non-creeping grout.

\subsubsection{Photoelastic Stressmeter}

Photoelastic stressmeters can be used for monitoring stress change (RKE/PB 1984, p. 4-68). The stressmeter consists of a cylindrical glass plug with an axial hole and a light source and filters. 
The meter is bonded around its periphery into a borehole, the light source is toward the bottom of the borehole, and the outer face of the plug is viewed through a hand viewer. The number of fringes is directly proportional to shear strain in the glass.

The primary advantage of the photoelastic stressmeter is that it has performed well at ambient temperature.

The limitations of the photoelastic stressmeter are:

- The stressmeter provides only a point measurement.

- The stressmeter is not proven for monitoring at elevated temperatures.

\subsubsection{Recommended Procedures for Determining Stress Change}

All of the procedures described above, with the exception of the flat jacks, provide point measurements. The actual stress within a rock mass may vary from point to point, depending on local geologic features, and a single point measurement may be misleading. For reliable stress change monitoring, measurements should be made at more than one location.

\subsubsection{Rock Mass Strength}

The following data acquisition procedures can be used for determining rock mass strength:

- Compressive strength of rock mass: in-situ triaxial compression test

- Shear strength: in-situ direct shear test, in-situ torsional shear test

These procedures are described below. Knowledge of the rock mass strength comes largely from empirical estimates and the scaling of tests on intact rock; consequently, emphasis is not given in this section to measurement of the rock mass strength. It is not envisioned that these tests will be made at elevated temperatures.

\subsubsection{In-Situ Triaxial Compression Test}

An in-situ triaxial test can be performed by separating a vertical cylinder of rock from the surrounding rock by coring, inserting curved flat jacks into the annular space and applying a radial pressure through these jacks while a vertical pressure is applied to the top of the hydraulic jack (RKE/PB 1984, p. 4-71, 4-72). Displacement at the top and sides of the cylinder would be measured.

The size of the cylinder should be large relative to the spacing of the rock discontinuities yet small enough that the test could be conducted within the constraints of practicality. The practical limit is determined by the size of the hydraulic jack and load cell that can be used to apply and measure the vertical load. Highly stressed and possibly fractured rock may make it difficult to drill the required cylindrical specimen. 
For example, with a 450-mm diameter cylinder, and considering an unconfined rock mass strength of $80 \mathrm{MPa}$, the required vertical load would be 12.72 Meganewtons (MN). A modest confinement would drastically increase the axial load required for failure. Based on practical load limitations, it appears that about a $450-\mathrm{mm}$ cylinder would be the largest size cylinder to be considered. In that case, the ratio between discontinuity spacing and sample size is rather small and the value of the test data would be limited unless a large number of tests were performed to provide a statistically significant sample. This test could also provide additional data on rock mass deformability and Poisson's ratio.

\subsubsection{In-Situ Direct Shear Test}

An in-situ direct shear test consists of preparing a test block at the surface of an opening, creating a normal load using a reaction or anchor system, and then shearing the block under a lateral thrust to determine the peak and residual shear strengths (RKE/PB 1984, p. 4-74). Normal and shear displacements are monitored during the shearing phases. The test can be repeated at increased normal loads.

\subsubsection{In-Situ Torsional Shear Test}

An in-situ torsional shear test consists of installing an anchor bolt from the surface of an opening that is anchored below the intended test horizon (RKE/PB 1984, p. 4-75). The bolt is tensioned to hold the test core together while a core is drilled around the anchor bolt below the test horizon. The annular space around the test core is filled with weak material, an increased normal load is applied by tensioning the anchor bolt, and a torque is applied to the upper portion of the core to determine peak and residual shear strengths. Rotational displacements are measured during the application of the torque. The test can be repeated at increased normal loads on different samples. Additional data on rock mass deformability may be obtained from this test.

\subsubsection{Recommended Procedures for Determining Rock Strength}

None of the methods described herein are likely to provide unequivocal answers about rock mass shear and triaxial strength because of the small scale of the tests relative to the spacing of discontinuities. In terms of the amount, quality of data, and ease of interpretation, the in-situ triaxial compression test is recommended. However, it is also recommended that a small number of tests be conducted. These tests should not be counted as an essential part of the overall stability assessment strategy. Instead, emphasis should be placed on monitoring opening performance to establish deformational stability criteria rather than criteria based on rock strength.

\subsubsection{Temperature Measurements}

Temperature is recognized as one of the most important and easily measured parameters of the PC period. Temperature sensors are small, inexpensive, and can be collocated with other instruments within the same borehole. Temperature measurements may also be required to provide temperature compensation of many of the deformation and stress measuring instruments. 
The following sections will describe the various types of temperature sensors available for this purpose.

\subsubsection{Thermocouple}

A thermocouple is composed of a cable containing two conductors of dissimilar metals, with one end of each conductor joined together to form a measuring junction (Omega 1999, p. z-21, z-22). At any temperature above absolute zero, a small voltage is generated at the sensing junction and measured between the two conductors at the other end of the cable. This voltage is proportional to the measuring junction temperature but it cannot be read directly because connecting a type of readout device or transmitter will make two more unwanted thermocouple connections. To solve this problem, thermocouples must be referenced with the readout device or transmitter connected to similar metals so that another thermocouple is not formed. Today's transmitters and system input cards have internal electronic reference junctions that allow direct connection to the thermocouple leads.

Thermocouples are widely used in applications requiring modest accuracy and in large installations requiring the thermal acquisition of data. Thermocouples provide low cost per point temperature measurement, are simple and rugged, and the numerous thermocouple types can cover a broad range of temperatures.

\subsubsection{Resistance Temperature Detector}

The RTD is a temperature-sensing resistor consisting of a metal wire with known, reproducible, and stable temperature-resistance characteristics that is wound on a non-conducting core (Omega 1999, p. z-33, z-34). The RTD usually forms a leg in a Wheatstone bridge circuit. Typical connections consist of three wires, the third wire being used for compensating lead line resistance. RTDs are available for temperature measurements in the range from $-220^{\circ} \mathrm{C}$ to $+2,750^{\circ} \mathrm{C}$.

Wire material is usually platinum, copper, or nickel, or an alloy of these materials. Platinum has the greatest accuracy, linearity, stability, and repeatability. Copper-nickel alloys have the greater sensitivity.

\subsubsection{Thermistors}

Like the RTD, the thermistor is also a temperature-sensitive resistor. While the thermocouple is the most versatile temperature transducer and the platinum RTD is the most stable, the word that best describes the thermistor is sensitive. Of the three major categories of sensors, the thermistor by far exhibits the largest output change with temperature.

Thermistors are generally composed of semiconductor materials (Omega 1999, p. z-36). Although positive temperature coefficient units are available, most thermistors have a negative temperature coefficient; that is, their resistance decreases with increasing temperature. 
The thermistor is an extremely non-linear device that is highly dependent upon the process parameters. Consequently, manufacturers have not standardized thermistor temperature curves to the extent that RTD and thermocouple curves have been standardized. Thermistors are also much more fragile than RTDs or thermocouples and they must be carefully mounted to avoid crushing or bond separation.

\subsubsection{Infrared Sensors}

Infrared sensors measure the amount of radiation emitted by a surface (Omega 1999, p. z-63, z64). Electromagnetic energy radiates from all matter regardless of its temperature. In many processes the energy is in the infrared region. As the temperature goes up, the amount of infrared radiation and its average frequency go up.

Different materials radiate at different levels of efficiency. This efficiency is quantified as emissivity, a decimal number or percentage ranging between 0 and 1 or between 0 percent and 100 percent. Most organic materials, including skin, are very efficient, frequently exhibiting emissivities of 95 percent. Most polished metals on the other hand, tend to be inefficient radiators at room temperature, with emissivity or efficiency often 20 percent or less.

To function properly, an infrared measurement device must take into account the emissivity of the surface being measured. These values can often be looked up in a reference table. A practical way to measure temperature with infrared sensors when the emissivity level is not known is to force the emissivity to a known level, by covering the surface to be measured with a piece of masking tape or a highly emissive paint.

\subsection{GENERAL INSTRUMENTATION}

The following sections will discuss the types of instruments that may be used to transmit data in a stand-alone configuration or in conjunction with other devices to achieve the methodology as described in Section 6.4. These types include:

- Vibrating wire transducers

- Multi-point borehole extensometers

- Inclinometers

- Tiltmeters

- Piezometers

- Humidity transmitters

- Pressure transmitters

\subsubsection{Vibrating Wire Transducers}

Vibrating wire transducers are used as a type of signal transmitter in pressure sensors for piezometers, borehole pressure cells, deformation gauges and directly as surface or embedment strain gauges. 
The operating principle for vibrating wire transducers is that a length of steel wire is clamped at both of its ends and tensioned so that it is free to vibrate at its natural frequency. Just like a piano string, the frequency of vibration varies with the tension in the wire. Therefore, the wire can be used as a strain gauge by plucking the wire, measuring the natural frequency, and relating any frequency change to strain. The wire is plucked magnetically by an electrical coil attached near the midpoint of the wire, and either the same coil or a second coil is used to measure the frequency of vibration.

There are two methods of wire plucking and reading, the pluck-and-read method and the continuous-excitation method. (Dunnicliff 1988, section 8.4.9)

The pluck-and-read method entails application of one or more voltage pulses to the coil, thereby creating a magnetic attraction that causes the wire to vibrate. The coil then becomes a listening device because wire vibrations cause an alternating voltage to be induced in the plucking coil that is of a frequency identical to the natural frequency of the vibrating wire. The voltage signal is transmitted along the signal cable to a frequency counter, which is used to measure the time for a predetermined number of vibration cycles.

The continuous excitation method entails a similar procedure to initiate vibration, but a second coil is used to detect the frequency. The signal is fed back to the driving coil so that it applies a continuously pulsing voltage, with a frequency identical to the natural frequency of the vibrating wire. As the wire frequency changes, so does the driving frequency. The wire frequency can be determined by measuring the time for a predetermined number of vibration cycles as in the pluck-and-read method above. Alternatively, the pulsing voltage can be converted continuously, by a frequency-to-voltage converter, into a voltage that is directly proportional to the pulse frequency. This voltage signal can then be transmitted to a data acquisition system where monitoring, trending, and alarm functions can take place.

The primary advantage of the frequency signal is that the signal contains the required information in the form of a frequency rather than a resistance or voltage. Therefore, the undesirable effects involving signal cable resistance, contact resistance, leakage to ground, and radio frequency or electromagnetic interference are negligible. Very long cable lengths can be routinely accommodated by using unshielded cable.

The major disadvantages of vibrating wire transducers have been wire corrosion, creep of the vibrating wire under permanent tension, and slippage at the wire anchoring points, all of which usually result in a reduction in the vibrating frequency that is unrelated to strain, causing a zero shift to occur. Corrosion can be minimized by the proper selection of materials for the environment anticipated and hermetically sealing the cavity that surrounds the wire. Attempts to minimize corrosion in vibrating wire pressure transducers by continuously circulating dry nitrogen through them have proved difficult to maintain.

\subsubsection{Multi-Point Borehole Extensometers}

Fixed borehole extensometers are defined as devices installed in boreholes in soil or rock for monitoring the changing distance between two or more points along the axis of the borehole, 
without the use of a movable probe (Dunnicliff 1988, section 12.7). When the location of one measurement point is determined with respect to a fixed reference datum, the device provides absolute deformation data.

Borehole extensometers are installed within boreholes to monitor axial dimension changes. Borehole extensometers consist of a series of anchors with attached rods or wires. The rods or wires extend to the electronics located at the mouth of the borehole, where any movement of the anchors is sensed by measuring the corresponding movement of the rod or wire (ASTM D 4403-84, section 3.2.1). If one downhole anchor is used, the device is referred to as a singlepoint borehole extensometer. Several downhole anchors can be located in a single borehole, each with an attached rod from the downhole anchors to the collar anchor, to create a multi-point borehole extensometer.

Various types of extensometers are available. The differences in the types include anchor type, use of rods or wires to link the anchors to the head (located at the mouth of the borehole), and the use of mechanical or electrical sensors in the head.

There are four general types of anchor: expanding wedge (rock bolt), spring-loaded, grouted, and hydraulic. The expanding wedge anchor is generally preferable for single- and double-position extensometers in rock. The spring-loaded anchor is useful in competent rock where smooth uniform boreholes can be drilled. The grouted anchor is the preferred anchor for downwarddirected holes in rock and for horizontal boreholes that can be angled slightly downward. Also, grouting can be used in conjunction with any of the anchor types listed. The hydraulic anchor is used primarily in soft ground.

Rod-type extensometers have a simpler design than wire types. Rods should be individually sleeved and, if used at other than ambient temperature, which will most likely be the case in the repository, a rod material with a very low thermal expansion coefficient will be required in order to reduce or eliminate the need for corrections resulting from thermal strain. Arguments have been made that rod tensioning increases inaccuracies due to friction because boreholes are usually not straight, and tensioned rods are forced against their sleeves; however there appear to be no test data that address this contention. Clearly the use of low-friction sleeve material such as teflon would limit this problem.

Mechanical sensors are either dial indicators or depth micrometers. Electrical sensors are Linear Variable Displacement Transducers (LVDTs), direct current LVDTs, linear potentiometers, strain-gauged cantilevers, vibrating wire transducers, or magnetostrictive (sonic probe) transducers. It is recommended that whenever an electrical sensor is used, provisions should be made for mechanical readout as a periodic check on the accuracy of the electrical system and as a backup capability.

The advantages and limitations of commercially available borehole extensometers are listed in Table 8 . 
Table 8. Advantages and Limitations of Rod-type Borehole Extensometers with Remote Electrical Readout

\begin{tabular}{|l|l|l|}
\hline \multicolumn{1}{|c|}{ Transducer Type } & \multicolumn{1}{|c|}{ Advantages } & \multicolumn{1}{c|}{ Limitations } \\
\hline Vibrating wire & $\begin{array}{l}\text { Lead wire effects are minimal } \\
\text { Can use long lead wires }\end{array}$ & $\begin{array}{l}\text { Complex mechanism } \\
\text { Costly } \\
\text { Limited Range }\end{array}$ \\
\hline Magnetostrictive & $\begin{array}{l}\text { Low hysteresis } \\
\text { High range } \\
\text { Easy to install } \\
\text { Easy to detach and re-use } \\
\text { Minimal lead wire effects }\end{array}$ & $\begin{array}{l}\text { Costly } \\
\text { Danger of de-magnetizing sensors } \\
\text { Transducer sensitive to temperature }\end{array}$ \\
\hline LVDT & $\begin{array}{l}\text { Low hysteresis } \\
\text { High sensitivity }\end{array}$ & $\begin{array}{l}\text { Complex mechanism } \\
\text { Costly } \\
\text { Lead wire effects }\end{array}$ \\
\hline Direct Current-LVDT & $\begin{array}{l}\text { Very high hysteresis } \\
\text { High sensitivity } \\
\text { High DC output } \\
\text { Lower lead wire effect than LVDT }\end{array}$ & $\begin{array}{l}\text { Complex mechanism } \\
\text { Costly }\end{array}$ \\
\hline Linear potentiometer & $\begin{array}{l}\text { Simple readout } \\
\text { High DC output } \\
\text { Low lead wire effects }\end{array}$ & $\begin{array}{l}\text { Complex mechanism } \\
\text { Costly }\end{array}$ \\
\hline
\end{tabular}

\subsubsection{Inclinometers}

An inclinometer is a device used for measuring the deviations perpendicular to the axis of a liner or casing installed in a borehole (ASTM D 4622-86, section 2.1). The probe contains a gravitysensing transducer designed to measure inclination with respect to the vertical. The casing may be installed in a near vertical alignment, so that the inclinometer provides data for defining subsurface horizontal deformation. Inclinometers are also referred to as slope inclinometers or slope indicators (ASTM D 6230-98, section 3.2).

Most inclinometers have four major components (ASTM D 6230-98, section 4):

- A permanently installed casing, made of plastic, aluminum alloy, fiberglass, or steel. This casing acts to guide the probe and usually has four tracking grooves for controlling the orientation of the probe. The four grooves are spaced at $90^{\circ}$.

- A portable probe containing a gravity sensing transducer.

- A readout unit that provides an indication of probe inclination and also provides power to the probe.

- A graduated electrical cable that links the probe to the readout unit.

In some probes, a cantilevered pendulum with resistance strain gauges, vibrating wire, or inductive transducers is used to measure casing deflection. Other probes use the Wheatstone bridge principle, the force balance accelerometer principle, or a differential transformer. The 
electrical output from the probe is measured at the readout unit and converted to provide a visual display or reading. The probe with a force balance accelerometer has become the most widely used type (Dunnicliff 1988, section 12.8.1).

After installation of the guide casing, the probe is lowered to the bottom and an inclination reading is made. The probe is then incrementally raised while additional inclination readings are made. This provides data for determining the initial casing alignment. The differences between these initial readings and subsequent set of readings define any change in inclination. Provided that one end of the casing is permanently fixed or referenced to a datum point, the absolute horizontal deformation can be calculated at any point along the casing.

The frequency of observations depends upon several factors, the most important of which is the rate of movement. It is necessary to read inclinometers frequently after initial installation and, based on these readings, to adjust the interval of observations accordingly. The observations should coincide with readings from other types of instrumentation such as seismicity, multi-point borehole extensometers, and piezometers.

\subsubsection{Tiltmeters}

Tiltmeters can be used to monitor the change in inclination of points in the ground. A tiltmeter consists of a gravity-sensing transducer within an appropriate housing, for installation below the surface of the ground (Dunnicliff 1988, section 12.4). The subsurface versions are usually fixedin-place within boreholes.

Applications of tiltmeters include monitoring of ground subsidence that is expected to contain a rotational component. They can also be used for monitoring other geodetic events or the effects of seismic activity. The precision of a tiltmeter is usually expressed in radians or arc-seconds.

Pendulum-actuated vibrating wire transducers are available for embedment below the surface of the ground within a borehole. Two configurations are currently available. First, a pendulum is rigidly attached to the top of the tiltmeter such that tilt causes bending strains in the pendulum, and the strains are monitored by two vibrating wire strain gauge transducers, one on each side of the pendulum in the plane of tilting.

The second configuration has four vibrating wire strain gauge transducers spaced around the pendulum for monitoring tilt in two vertical planes, 90 degrees apart. In this configuration, the vibrating wire transducers span between the pendulum and instrument housing. Because the strain gauge transducers are mounted on opposite sides of the pendulum, in either the two or four unit configuration, tilting causes equal and opposite strains in the transducers and temperature effects are eliminated.

\subsubsection{Piezometers}

The term "piezometer" is used to indicate a device that is sealed within the ground so that it responds only to the groundwater pressure around itself and not to groundwater pressures at other elevations. Piezometers are commonly used to monitor pore water pressure and joint water 
pressure. The basic principle of operation of all piezometers is that a porous element is placed in the ground so that the soil/water is continuous through the pores of the element (Hanna 1985, section 3.4). This water is collected inside the element unit. The measurement of either the water level or the water pressure in the container unit will determine the pore water pressure in the ground at the location of the piezometer.

Applications for piezometers fall into two general categories: first, for monitoring the pattern of water flow, and to provide an index of soil or rock mass strength (Dunnicliff 1988, section 9.1). Examples in the first category include monitoring subsurface water flow during dry-out to determine the in-situ permeability. In the second category, monitoring of pore water pressure allows an estimate of effective stress to be made and, thus, an assessment of strength.

Piezometers can be grouped into those that have a diaphragm between the transducer and the pore or joint water and those that do not. Instruments in the first group are piezometers with vibrating wire, pneumatic, or electrical resistance strain-gauge transducers. Instruments in the second group are open standpipe and hydraulic piezometers.

\subsubsection{Humidity Transmitters}

Relative humidity in the waste package environment is probably as important for the assessment of the performance of waste package materials as water saturation level in the rock mass (CRWMS M\&O 1996, section 6.4.2). The spatial distribution of relative humidity and its temporal variations are also important for understanding some processes of moisture movement, such as binary diffusion. In the PC program, relative humidity will be measured in sealed boreholes and in alcoves/drift exhaust/tunnel. The range of the expected humidity depends on the location of the measurement. In the region near the emplacement drifts, the humidity may decrease from an initial value of 80 to 100 percent, to a very low level, such as 10 to 20 percent. In a region where extensive condensation may occur, such as in the pillars, the relative humidity may increase from ambient to 100 percent. The location of these regions will be determined by scoping model calculations. Sensitivity analyses will be required to determine the accuracy requirement for these humidity tests.

Most manufacturers use a type of capacitance measurement to detect humidity. One method is to deposit a layer of porous aluminum oxide on a conductive aluminum substrate and coat the oxide with a thin film of condensate from evaporated gold. The aluminum oxide is a dielectric, or a nonconductor of electric current; silicon polymers may also be used as the dielectric. The aluminum substrate and gold film act as the electrodes of a capacitor. Water vapor in the air penetrates through the gold layer and is absorbed by the aluminum oxide. The amount of water vapor absorbed determines the capacitance registered by the sensor.

The boreholes to be used for humidity measurement will be from 7.5 to $10 \mathrm{~cm}$ in diameter. If packers are used, the hole must be sufficiently straight to allow installation of the packer assembly, which is usually a few meters in length. If cement grout is used for sealing the borehole, then the straightness requirement is not as important. The humidity transmitters can also share a borehole with other measurement devices such as temperature sensors and pressure transmitters. 


\subsubsection{Pressure Transmitters}

Gas/air pressure will be measured both in sealed boreholes and in alcoves/drifts/tunnels in the repository. In a sealed borehole, the gas/air pressure will be measured using a pressure transmitter. The gas pressure will be measured at strategic locations so that the effect of the pressure gradient on moisture movement can be determined. Those locations include the dry-out region, the condensation region, and the transient region between them. Scoping model calculations will be conducted to determine those locations with respect to the emplacement drifts.

There are several methods for measuring the gas pressure in a rock mass. Each of these methods involves using a pressure transducer or transmitter (CRWMS M\&O 1996, section 6.4.1). The difference is in the fielding of the instruments. The various methods include (1) installing a pressure transmitter in a section of a borehole isolated by packers, (2) sealing a pressure line in a borehole with its open end located at the measuring point and connecting the other end to the pressure transmitter located in a readily accessible portion of the alcove/tunnel, and (3) sealing a pressure transducer within a section of a borehole using a technique such as cement grout.

The first method requires using a pressure transmitter that is rated to be used in high-temperature environments. Such high-temperature gas pressure transmitters are commercially available. The first method also requires the installation of high-temperature packers.

The second method requires only ambient temperature pressure transmitters, which are reliable for long-term measurements. Sealing a pressure line in the second method can be achieved by using either packers or other methods such as cement grout. High-temperature packers are expensive but fairly easy to install. Cement grout is not expensive, but requires attention when installing so that the borehole can be sealed without plugging the pressure line. The second method also requires verification that the pressure measured at one end of the pressure line is the same as at the other end, especially when the temperature at the measurement location is different from that where the pressure transmitter is located. This is probably the most important concern about this method, but can easily be accommodated by temperature compensation.

\subsection{GENERAL INSTRUMENTATION ISSUES}

Many of the in-situ data acquisition techniques that may be employed as part of the repository PC program have been discussed previously. This section will present issues that may be applicable to all types of instruments and will attempt to provide insight as to how these issues can be addressed.

\subsubsection{Instrument Reliability}

The overriding desirable feature of the instrumentation to be used in the PC program is reliability. The data the instruments measure and transmit must be able to be trusted as valid data because the direction of the nuclear waste program will depend on that data. Lowest cost of an instrument should never be allowed to dominate the selection because the least expensive instrument is not likely to result in the minimum total cost. In evaluating the economics of 
particular instruments, the overall cost of procuring, calibrating, installing, and maintaining them should be addressed.

The state of the art in hardware design is far ahead of the state of the art in user technology. It will be the responsibility of the PC testing and design team to develop an adequate understanding of the reasons and technology behind the selection of the instruments. They should discuss the application with the manufacturers' geotechnical engineers and seek out any possible limitations of the proposed instruments. The instruments should have a good performance record and have maximum durability for their anticipated environment. As an example, the results from the drift scale heater test should provide a good indication of the survivability rate of various types of instruments.

Personnel will also play a large part in the reliability of a particular instrument's performance. Extreme care must be taken in handling the instruments during receiving, warehousing, and installation. To ensure reliability, the instruments must also be calibrated properly, within the ranges specified by the manufacturer, and must be installed correctly. No instrument will provide a reliable readout if it is installed incorrectly. Finally, all required maintenance and recalibration must be accomplished on a regular schedule. In addition, there should be an adequate supply of spare parts on-site to facilitate quick repairs.

\subsubsection{Instrument Redundancy}

During the PC period, underground environmental conditions for in-situ sensors and instrumentation will be far from ideal. Factors such as humidity, dust, radiation, and temperature variations, together with impacts from installation and handling methods, could damage or eventually destroy the sensors. In the design of the test and monitoring system, redundancy of instrumentation will be employed to provide backup should a specific sensor fail. In addition, some attrition of instruments is anticipated during the performance of a specific test.

\subsubsection{Instrument Installation}

To conduct monitoring of the rock mass around the emplacement drifts, observation drifts will be excavated adjacent to the emplacement drifts (CRWMS M\&O 2000, section 5.4.1.2). Alcoves will be developed off of the observation drifts to permit larger coverage of the thermally perturbed unsaturated zone. Boreholes from the observation drifts will extend toward the emplacement drifts and will contain the majority of the instrumentation for the long-term, in-situ data collection activity. The primary purpose of the observation drifts will be to facilitate the installation of the instrumentation necessary for gathering data in support of the PC program. Interference with other activities such as construction, emplacement, etc., should not be a concern from the observation drift area.

It may be possible to allow selected boreholes to penetrate the walls of the emplacement drift, allowing instrumentation to be inserted directly into the emplacement drift and then withdrawn. Instrumentation would be installed in the boreholes from the observation drifts and, if repair or

re-calibration is required, could be removed and reinserted. In the case of instruments that must 
be grouted in place, additional boreholes may have to be drilled in the event of instrument failure.

Should instrumentation be required to be installed off the main drifts or in the exhaust portions of the repository, every effort will be made to maintain the required clearance envelopes. Interference from an instrument installation with construction or emplacement equipment will be avoided.

\subsubsection{Maintenance of Instruments}

As stated previously, a majority of the instruments for gathering in-situ data for PC will be installed within boreholes from the observation drifts. The observation drifts will be accessible by personnel, which will allow the instruments to be removed for periodic calibration and then reinstalled. Other maintenance activities could be the removal and repair of the particular components of the instrument should the device fail to operate properly. It is anticipated that detailed maintenance records will be kept for each instrument, and, when the records indicate that an instrument should be replaced, the new sensor or instrument could be installed, and the collection of PC data will continue. During the PC program, the option of replacing instruments shall be maintained, where possible, to address situations where sensor failure will lead to data gaps or questions concerning the integrity of the data.

\subsubsection{Instrument Longevity}

The PC program shall support a deferral of repository closure for up to 300 years after initiation of waste emplacement (Stroupe 2000, Attachment 1, p. 1). Because no instrument can be expected to last for this long a period, especially in the expected environment, a removal and replacement program will need to be considered. Technology is advancing at an exponential rate. It is anticipated that future versions of instrumentation will be able to make measurements with increased accuracy. The geotechnical instrumentation field, while small, should take advantage of the developments made in other instrumentation sectors, such as petrochemical, power, manufacturing, transportation, etc., and replacement instrumentation may also provide for increased functionality. 


\section{CONCLUSIONS}

The Yucca Mountain Project will implement a PC program that tests and evaluates the natural and engineered barrier systems of the repository to predict post-closure waste confinement and isolation performance. This program will rely on in-situ monitoring, field and laboratory tests, and experiments to collect data during repository construction and operation, which will be used to confirm predictions, evaluate pre-closure performance, and recommend corrective actions or repository closure. This analysis has focused on discussions regarding the in-situ methods and instruments necessary to transmit the data to a data acquisition system for further analysis, evaluation, and storage.

The Performance Confirmation Data Acquisition/Monitoring System Description Document, once approved, will ultimately determine the parameters to be measured in support of the PC program. This document will present the specific criteria that must be satisfied by the design of the PC data acquisition system. This system description document is scheduled to be formally baselined by the end of fiscal year 2001 .

To predict the performance of the Yucca Mountain site relative to the standards set by governing regulations and criteria, there must be adequate information regarding the properties and characteristics of the geologic system and the engineered systems used to operate the repository. The basic strategy of the PC program, as discussed in section 6.3 , is that in-situ data will be required to validate the computer models used to predict the performance of the repository. These decisions will be finalized in the years ahead.

Section 6.4 of this analysis discussed various methods of acquiring data and the results of that discussion are presented below.

Seismic measurements - Seismic monitoring is already underway in the Exploratory Studies Facility under the historical and current seismicity field work package. Any future work will be a continuation of this program. It is anticipated that ground motion measuring stations will be located throughout the subsurface network of the repository during the PC monitoring period.

Rock mass hydrologic properties - Numerous methods of acquiring hydrologic data were discussed in Section 6.4.2. These methods do not have advantages over each other and are dependent upon the type of hydraulic conductivity (low or high) of the zone of interest. Once more information is obtained concerning the zone of interest, the appropriate test can be implemented to obtain the necessary information.

Rock mass pneumatic properties - This test, as discussed in Section 6.4.3, can be implemented in the particular zone of interest to determine air permeability data.

Rock mass deformability - Test locations should be representative of typical in-situ conditions. In order to adequately sample the rock mass, it is necessary to test at a representative scale, which will be determined by the fracture spacing. Rock is a naturally variable material requiring sampling at numerous locations according to the degree of variability expected. 
The rigid-plate jacking test provides viable data for deformability of the disturbed rock zone and, provided that test locations are carefully trimmed using controlled excavation methods, of undisturbed rock mass. Multi-point borehole extensometers, as discussed in Section 6.5.2, can also be used throughout the repository horizon to provide deformability data.

In-situ stress and stress change - When planning procedures for in-situ stress measurements, it is important to recognize that the purpose is to determine the initial state of stress in the rock prior to excavation. Any opening made to determine stress will cause a fundamental change in stress conditions, a change that is often difficult to predict with certainty. The procedures that should be followed when measuring stress include:

- Utilize excavation techniques that minimize disturbance and, therefore, avoid significant inelastic behavior.

- Select points at the opening where rock is sound and its behavior will not be influenced by geologic structure.

- Complete relief of the stress on the initial opening by measuring the strain change; the strain change must be sufficient to allow for accurate measurement.

- Determine the elastic material properties of the rock.

- Determine the initial stress state from the measured strains.

The locations for measurement should be selected with great care. The initial opening in the rock, the surface strains of which need to be observed, must be smooth and free of defects. The rock in which the opening is made must be sufficiently competent to ensure that the opening will behave elastically and that localized failure or non-elastic behavior of the rock surface will not occur. In this manner the stress concentrations around an opening can be predicted and the measured surface strain evaluated to provide an assessment of the virgin stress field. Strain on the opening surface must be measured at locations where the deformability of the strain measuring scale is representative of the rock mass as a whole. The strain measurement location must, therefore, be devoid of significant rock fractures, inclusions, or jointing.

The following methods appear worthy of consideration:

- Miniature USBM gauge with overcoring

- Doorstopper gauge with overcoring

- Hydraulic fracturing

All of the procedures described in Sections 6.4.5 and 6.4.6, with the exception of the flat jacks, provide point measurements. The actual stress within a rock mass may vary from point to point, depending on local geologic features. Thus, a single point measurement may be misleading. For reliable stress change monitoring, measurements should be made at more than one location. 
Rock mass strength - None of the methods described in Section 6.4 .7 are likely to provide unequivocal answers about rock mass shear and triaxial strength because of the small scale of the tests relative to the spacing of discontinuities. In terms of the amount and quality of data and ease of interpretation, the in-situ triaxial compression test is recommended. However, it is recommended that a small number of tests be conducted. These tests should not be counted as an essential part of the overall stability assessment strategy. Rather, emphasis should be placed on monitoring the opening performance to establish deformational stability criteria rather than criteria based on stress and strength.

Temperature measurements - Temperature is recognized as one of the most important and easily measured parameters during the PC period. Temperature sensors are small, inexpensive, and can be collocated with other instruments within the same borehole. Temperature measurements may also be required to provide temperature compensation of many of the deformation, pressure, and stress instruments. It is recommended that a diverse selection of temperature sensing devices be utilized so data can be validated by independent means.

A short discussion concerning general instrumentation, anticipated to be used in the PC program, was presented in Section 6.5 of this analysis. These types of devices are manufactured by a variety of manufacturers and will be competitively bid upon completion of the specification sheets. Of primary concern is the ambient operating temperature of most of these devices. Efforts are under way to investigate the feasibility of operating these devices in the elevated temperatures of the repository.

Section 6.6 of this analysis addressed issues which are common to all of the types of instrumentation discussed previously. Issues such as reliability, redundancy, maintenance, and longevity were presented.

This document may be affected by technical product input information that requires confirmation. Any changes to the document that may occur as a result of completing the confirmation activities will be reflected in subsequent revisions. The status of the input information quality may be confirmed by review of the Document Input Reference System database. 
INTENTIONALLY LEFT BLANK 


\section{REFERENCES}

\subsection{DOCUMENTS CITED}

CRWMS M\&O (Civilian Radioactive Waste Management System Management and Operating Contractor) 1996. Test Design, Plans and Layout Report for the ESF Thermal Test. BAB000000-01717-4600-00025 REV 01. Las Vegas, Nevada: CRWMS M\&O. ACC: MOL.19970114.0166.

CRWMS M\&O 1997. Subsurface Repository Performance Confirmation Facilities. BCA000000-01717-0200-00011 REV 00. Las Vegas, Nevada: CRWMS M\&O. ACC: MOL.19970723.0142.

CRWMS M\&O 1998. Monitored Geologic Repository Test and Evaluation Plan. B00000000-01717-5705-00058 REV 02. Las Vegas, Nevada: CRWMS M\&O. ACC: MOL.19980729.0006.

CRWMS M\&O 1999a. Performance Confirmation Input Criteria. Input Transmittal EBS-SEI-99255.T. Las Vegas, Nevada: CRWMS M\&O. ACC: MOL.19990826.0071.

CRWMS M\&O 1999b. Classification of the MGR Performance Confirmation Data Acquisition/Monitoring System. ANL-PCA-SE-000001 REV 00. Las Vegas, Nevada: CRWMS M\&O. ACC: MOL.19990928.0154.

CRWMS M\&O 1999c. Performance Confirmation. 99 WP 12012383MI. Activity Evaluation, March 29, 1999. Las Vegas, Nevada: CRWMS M\&O. ACC:

MOL.19990413.0018.

CRWMS M\&O 1999d. Performance Confirmation In-Situ Instrumentation. TDP-PCAMD-000001 Rev 00. Las Vegas, Nevada: CRWMS M\&O. ACC: MOL.19990816.0215.

CRWMS M\&O 2000. Performance Confirmation Plan. TDR-PCS-SE-000001 REV 01. Las Vegas, Nevada: CRWMS M\&O. ACC: MOL.20000302.0312.

DOE (U.S. Department of Energy) 2000. Quality Assurance Requirements and Description. DOE/RW-0333P, Rev 9. Washington, D.C.: U.S. Department of Energy, Office of Civilian Radioactive Waste Management. ACC: MOL.19991028.0012.

Dunnicliff, J. and Green, G. E. 1988. Geotechnical Instrumentation for Monitoring Field Performance. New York, New York: John Wiley \& Sons.

TIC: 209854.

Dyer, J.R. 1999. "Revised Interim Guidance Pending Issuance of New U.S. Nuclear Regulatory Commission (NRC) Regulations (Revision 01, July 22, 1999), for Yucca Mountain, Nevada." Letter from Dr, J.R. Dyer (DOE) to Dr. D.R. Wilkins (CRWMS M\&O), September 3, 1999, 
OL\&RC:SB-1714, with enclosure, "Interim Guidance Pending Issuance of New NRC Regulations for Yucca Mountain (Revision 01)." ACC: MOL.19990910.0079.

Hanna, T.H. 1985. Field Instrumentation in Geotechnical Engineering. Series on Rock and Soil Mechanics. Volume 10,843. Clausthal-Zellerfeld, Germany: Trans Tech Publications. TIC: 209859.

Hardin, E.L. 1998. Near-Field/Altered-Zone Models Report. UCRL-ID-129179. Livermore, California: Lawrence Livermore National Laboratory. ACC: MOL.19980630.0560.

Omega 1999. The Temperature Handbook. Stamford, Connecticut: Omega Engineering TIC: 245764.

RKE/PB(Raymond Kaiser Engineers/Parsons Brinkerhoff) 1984. "Task V, Engineering Study Number 8, In Situ Instrumentation." Nuclear Waste Repository in Basalt; Project B-301. RHO-BWI-ES-017. Oakland, California: Raymond Kaiser Engineering.

TIC: 246172.

Stroupe, E.P. 2000. "Approach to Implementing the Site Recommendation Design Baseline." Interoffice correspondence from E. P. Stroupe (CRWMS M\&O) to Dr. D.R. Wilkins, January 26, 2000, LV.RSO.EPS.1/00-004, with attachment.

ACC: MOL.20000214.0480.

YMP (Yucca Mountain Project) 1998. Q-List. YMP/90-55Q, Rev. 5. Las Vegas, Nevada: Yucca Mountain Site Characterization Office. ACC: MOL.19980513.0132.

\subsection{CODES, STANDARDS, REGULATIONS AND PROCEDURES}

AP-3.10Q, Analyses and Models. Rev. 2, ICN 0. Washington D.C.: U.S. Department of Energy, Office of Civilian Radioactive Waste Management. ACC: MOL.20000217.0246.

ASTM D 4394-84. 1984. Standard Test Method for Determining the In-Situ Modulus of Deformation of Rock Mass Using the Rigid Plate Loading Method. Philadelphia, Pennsylvania: American Society for Testing and Materials. TIC: 231530.

ASTM D 4403-84. 1984. Standard Practice for Extensometers Used in Rock. Philadelphia, Pennsylvania: American Society for Testing and Materials. TIC: 231530.

ASTM D 4622-86. 1986. Standard Test Method for Rock Mass Monitoring Using Inclinometers. Philadelphia, Pennsylvania: American Society for Testing and Materials. TIC: 231530.

ASTM D 4623-96. 1996. Standard Test Method for Determination of In-Situ Stress in Rock Mass by Overcoring Method - USBM Borehole Deformation Gage. West Conshohocken, Pennsylvania: American Society for Testing and Materials. TIC: 242992. 
ASTM D 4645-87. 1987. Standard Test Method for Determination of the In-Situ Stress in Rock Using the Hydraulic Fracturing Method. Philadelphia, Pennsylvania: American Society for Testing and Materials. TIC: 231530.

ASTM D 4729-87. 1987. Standard Test Method for In-Situ Stress and Modulus of Deformation Using the Flatjack Method. Philadelphia, Pennsylvania: American Society for Testing and Materials. TIC: 231530.

ASTM D 4971-89. 1989. Standard Test Method for Determining the In-Situ Modulus of Deformation of Rock Using the Diametrically Loaded 76-mm (3-in.) Borehole Jack.

Philadelphia, Pennsylvania: American Society for Testing and Materials. TIC: 245311.

ASTM D 6230-98. 1998. Standard Test Method for Monitoring Ground Movement Using Probe-Type Inclinometers. West Conshohocken, Pennsylvania: American Society for Testing and Materials. On Order Library Tracking Number-1798

QAP-2-0, Conduct of Activities. Rev. 5, ICN 1. Washington, D.C.: U.S. Department of Energy, Office of Civilian Radioactive Waste Management. ACC: MOL.19991109.0221.

QAP-2-3, Classification of Permanent Items. Rev.10, ICN 0. Washington D.C.: U.S. Department of Energy, Office of Civilian Radioactive Waste Management. ACC: MOL.19990316.0006. 
INTENTIONALLY LEFT BLANK 


\section{ATTACHMENTS}

None. 